\title{
Environment, Absolute? The quality infrastructure of the planetary boundaries.
}

\author{
Sarah E. Cornell (email: sarah.cornell@su.se, Twitter: @sarahlizcornell) \\ Andrea S. Downing (email: andrea.downing@su.se, Twitter: @AndreaSDowning)
}

Stockholm Resilience Centre, Stockholm University, Sweden

This paper is a non-peer reviewed preprint submitted to EarthArXiv. It was prepared as a Discussion Paper for Germany's Physikalisch-Technische Bundesanstalt, but it reflects the views only of the authors, and the PTB cannot be held responsible for any use that may be made of the information in the document. 


\section{Environment, absolute?}

\section{The quality infrastructure of the planetary boundaries}




\section{Environment, Absolute? The quality infrastructure of the planetary boundaries.}

A Discussion Paper for the Physikalisch-Technische Bundesanstalt

May 2014

Sarah Cornell and Andrea Downing

We gratefully acknowledge helpful input from participants of the SRC workshop on quality matters: Miguel Mahecha, Jamila Haider, Catherine Downy, Anders Bjørn, Juan Carlos Rocha and Marco Campenní. We also thank all the scientists who provided views and examples that have informed this report.

\section{Stockholm Resilience Centre}

Stockholm Resilience Centre advances research on the governance of social-ecological systems with a special emphasis on resilience - the ability to deal with change and continue to develop.

The Stockholm Resilience Centre was established on 1 January 2007.

The centre is a joint initiative between Stockholm University and the Beijer International Institute of Ecological Economics at The Royal Swedish Academy of Sciences. The centre is funded by the Foundation for Strategic Environmental Research, Mistra.

The FORMAS-provided project Resilience and Sustainability: Integrated Research on Social-Ecological Systems, is an acknowledgement of Stockholm Resilience Centre also being a Swedish Centre of Excellence.

address Stockholm Resilience Centre, Stockholm University, SE-106 91 Stockholm, Sweden visiting address Kräftriket $2 \mathrm{~b}$ telephone +4686747060 info@stockholmresilience.su.se www.stockholmresilience.su.se 


\section{Summary}

Quality infrastructure plays a key role in sustainable development. Achieving a harmonious relationship between humanity and nature requires better measurement, monitoring and management of environmental processes, from local to global scales. Human-caused climate change, biodiversity loss, perturbation of Earth's biogeochemical cycles, and chemical pollution are global environmental processes where unsustainability has become evident. This report describes issues in the quality infrastructure for these processes.

\section{Planetary boundaries mark precautionary limits for critical environmental processes where the rate and scale of human perturbation is a global concern, because threshold changes in Earth system functioning present rising risks to society's activities. The concept was devised as a science agenda, not primarily as a framework for policy implementation. It has become an important concept for communication about sustainability, addressing multiple global processes together.}

The planetary boundaries concept depends critically on the quality of knowledge about global processes. The proposed planetary boundaries are based on decades of globally collated data. Further research and application requires improved information on states and trends in physical, chemical, biological, geological and socio-economic processes, operating across time and spatial scales, as well as improved means for integrating across these fields.

Each of the global change fields has different approaches to the global quality infrastructure. The processes of implementing quality infrastructures (there are multiple) in global environmental change sciences preceded the data gathering at a global scale. They have been developed ad hoc at regional scales. The resulting data patchiness and heterogeneity in quality is a well-known challenge for global science and policy.

Data and information management are a perpetual challenge in this research-led field. The science is intrinsically complex, and both the environmental and socio-political contexts are changing rapidly. The World Data System coordinates 52 specialist data centres in support of global cooperative research, but global data remain concentrated in a few countries. Research community incentives are lacking for improved data management and compliance.

Much can still be done to improve the usability and usefulness of data between communities. Approaches include 'essential variables', global data synthesis products for key periods or time-slices, use of proxies, and benchmarking systems linking model output and observational data. These all raise the importance of comprehensive metadata.
Climate change has a highly elaborated global quality infrastructure, bridging pure science to real-world policy implementation. The UNFCCC and IPCC processes are important in providing community coherence and coordination, method and data consistency and interoperability, and global coverage.

The biodiversity and ecosystem change domain is currently developing global infrastructure that retains essential links to locally specific realities. The $\mathrm{CBD}$ and its associated targets are mobilizing improvements in less developed regions of the world, with strong stakeholder involvement.

The biogeochemical cycles of $N$ and $P$ are an emerging issue of global concern, interacting with climate and biodiversity loss. Quality infrastructure exists for just some aspects of the cycles, at local to regional levels. The few global studies made in the 1990s no longer reflect environmental realities. Both science and policy are constrained by this partial picture. Researchers in this domain are calling for global assessments.

Chemical pollution shows the best and worst of a global quality infrastructure. Production processes are generally highly controlled environments. Less developed countries have less control, and many lack production and transfer registers. Loopholes mean pollution has tended to be exported, not mitigated or avoided. Commercial confidentiality and intellectual property systems mean accessible information is severely lacking about substances of concern in the environment. New substances are being produced all the time, yet regulation is reactive, not precautionary.

All these issues show extreme regional heterogeneity in data and information availability, policy, and research and response capacity. International development cooperation on environmental change is urgent and important.
Adaptive monitoring is needed when the environment is changing fast. Quality infrastructure for global change somehow needs to be dynamic and adaptive. This creates a tension with 'classic' quality systems, with consistency at their core. 


\section{SETTING THE SCOPE: THE QUALITY INFRASTRUCTURE FOR ENVIRONMENTAL}

SUSTAINABILITY

ANALYZING THE GLOBAL ENVIRONMENTAL SCIENCE QUALITY INFRASTRUCTURE ……...................................

UNDERSTANDING AND RESPONDING TO GLOBAL ENVIRONMENTAL CHANGE REQUIRES GLOBAL INFORMATION

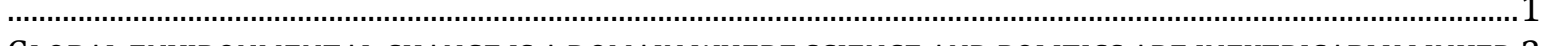

GLOBAL ENVIRONMENTAL CHANGE IS A DOMAIN WHERE SCIENCE AND POLITICS ARE INEXTRICABLY LINKED 3

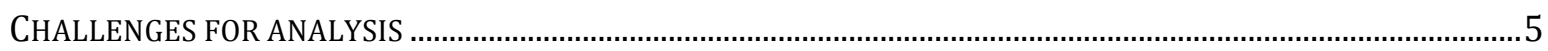

A QUALITY INFRASTRUCTURE FOR SUSTAINABILITY SCIENCE AND POLICY .......................................................6

2. THE PLANETARY BOUNDARIES: A DASHBOARD FOR “STRONG SUSTAINABILITY” ...........8

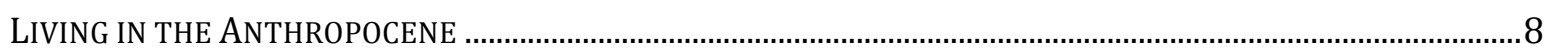

THE PLANETARY BOUNDARIES - A CONCEPT IN DEVELOPMENT ……........................................................... 10

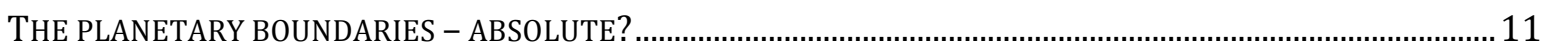

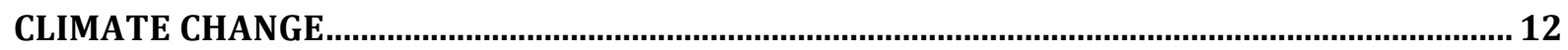

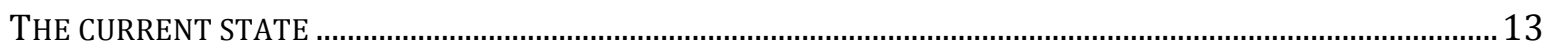

LINKS TO FRESHWATER USE, LAND USE, AND THE ATMOSPHERIC AEROSOL BURDEN ......................................13

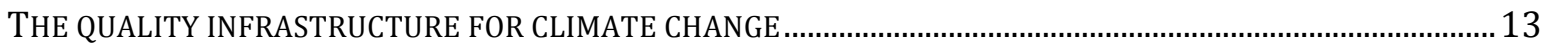

Basic data - for research and policy...............................................................................................

Meeting information needs - researching a changing world ............................................................15

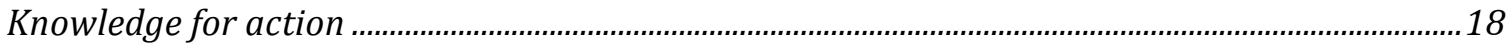

KEY ISSUES FACING THE CLIMATE CHANGE COMMUNITY ……........................................................................ 18

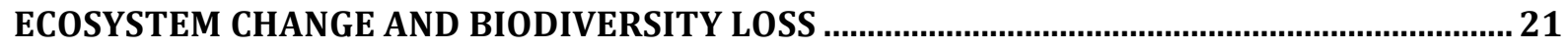

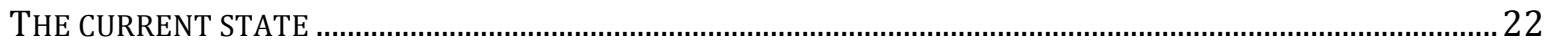

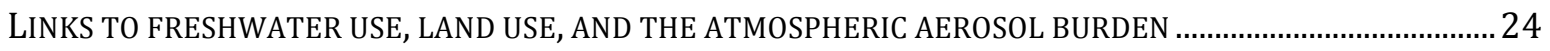

THE QUALITY INFRASTRUCTURE FOR ECOSYSTEM CHANGE AND BIODIVERSITY LOSS ........................................ 24

KEY ISSUES FACING THE BIODIVERSITY AND ECOLOGY COMMUNITY ……................................................... 28

PERTURBED BIOGEOCHEMISTRY: NUTRIENT ELEMENT RELEASES TO LAND AND AQUATIC

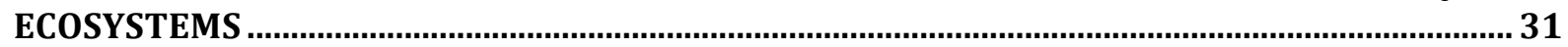

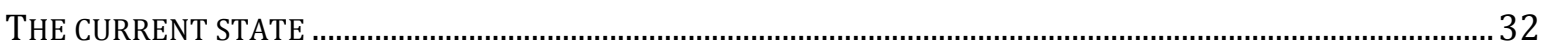

LINKS TO FRESHWATER USE, LAND USE, AND THE ATMOSPHERIC AEROSOL BURDEN ……................................ 32

THE QUALITY INFRASTRUCTURE FOR PERTURBED N AND P BIOGEOCHEMISTRY ................................................ 33

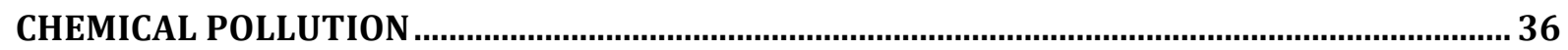

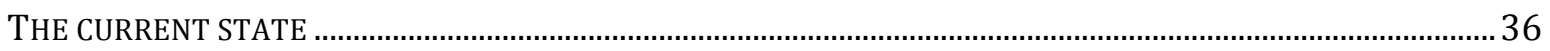

LINKS TO FRESHWATER USE, LAND USE, AND THE ATMOSPHERIC AEROSOL BURDEN …….................................. 37

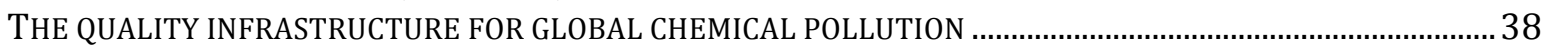

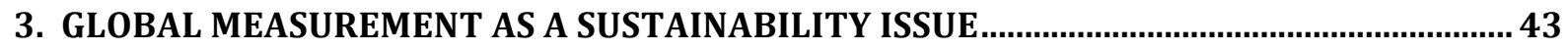

BUILDING WORLDWIDE CAPACITY AND INFRASTRUCTURE FOR GLOBAL CHANGE METROLOGY ....................... 43

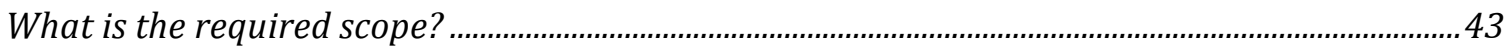

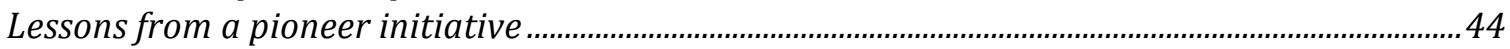

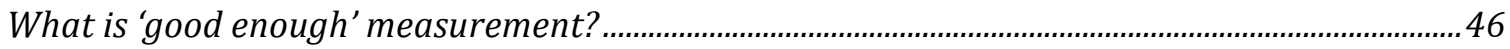

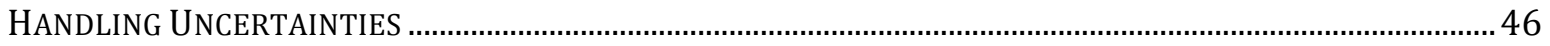

EQUITY AND FAIRNESS IN METROLOGY - THE DEVELOPMENT COOPERATION ANGLE ...................................... 48

'MANY KINDS OF KNOWLEDGE': NEW DEBATES ABOUT KNOWLEDGE CO-DEVELOPMENT …............................. 49

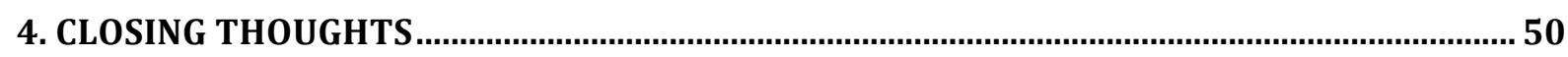




\section{Setting the scope: \\ The quality infrastructure for environmental sustainability}

\section{Analyzing the global environmental science quality infrastructure}

In this report, we address the quality infrastructure for key biophysical processes whose global scale and rates of change have made them become issues of major concern for sustainable development. We frame our analysis in terms of four aspects:

\footnotetext{
Metrology - development and use of measurement quantities, units and methods, and assessment of the suitability of instruments and quantification approaches.

Standardization - agreement, development and implementation of technical standards to enable coordination among multiple parties.

Conformity assessment - via systems for certification, accreditation and auditing.

Quality management - quality assessment and assurance of processes and products, testing, and continuous improvement.
}

This fourfold analytical structure differs slightly from other definitions of the term 'quality infrastructure'1. It has been defined to fit better with the sustainability science focus of this report, and the complex realities of the global environmental change context. This context differs in important ways from the more typical quality contexts of industrial production, trade, technology and communications. In these contexts, a given quality infrastructure relates to a particular, clearly defined set of issues, processes and products. Systematic attention can be given to issues including customer focus, process improvement, evidence gathering for decision-making, and the optimization of supply-chain relationships. Agreed standards can be mainstreamed throughout the organisation and its network.

In global change research, as in other fields of 'blue skies' innovation, all of these issues are more diffuse and interdependent than in organisations with more controlled (and controllable) environments. People engaged in research have different ways of identifying problems and their solutions than those working at the policy implementation and practice end of the 'pipeline'. Nevertheless, there is still a need for attention to quality matters in global change research. In particular, socio-economic globalization and global environmental change have placed a particular focus on the international quality infrastructure and its relationship to national and regional infrastructures and capacities.

\section{Understanding and responding to global environmental change requires global information}

Producing appropriate knowledge to inform decisions about global sustainability presents enormous quality management challenges. The processes of information gathering and knowledge production necessarily involve stakeholders from many disciplinary, sectoral and geographic backgrounds. These stakeholders use data sets pertaining to many diverse physical, chemical, biological, geological and socio-economic aspects of the Earth, relating to multiple timeframes, and spanning local to global scales. The information base for global sustainability includes experimental and observational data, model output, laypeople's understandings, and future projections of various kinds.

\footnotetext{
${ }^{1}$ See the PTB document Promotion of economic development in Technical Cooperation: Quality Infrastructure. www.ptb.de/q5.
} 
Different knowledge communities have divergent information needs, resulting in different preferred data formats and quality objectives, reflecting the fact that both individual research disciplines and policy areas have evolved along distinct paths. Very few research projects have policy information as a direct aim. Research goals are usually small and incremental in scope, and discipline specific,. Data are seldom produced to fit any global standard for global collation. These data are therefore mostly obtained in a piecemeal fashion; very few measures are truly global, and relatively few measures have uniform global coverage. This means that data gathering, collation and synthesis play a critically important role in global change science. Data generated in a particular context are often repurposed for other needs, and a great deal of research relies on the use of proxies - indirect measures that can serve as substitutes for the actual data that are needed. These kinds of synthesis and re-use activities require very high-quality metadata descriptions.

Global environmental change is undeniably a 'big data' activity2 , but it is also one that must interact effectively with many 'small data' realities. All these issues present substantial barriers to the global knowledge integration that is needed in order to respond to contemporary societal challenges.

In this report, we use the classic information hierarchy (Figure 1) to structure the discussion of these very complex issues. This hierarchy can also be seen as a way to frame the sequence from fundamental science (1), to applied research (2), and to society's decision making and policy processes (3).

It is important to be aware that although the hierarchy figure implies a one-way 'pipeline' flowing from academic theory to application and action, reality is of course a more complicated web.

Society's collective body of knowledge informs the choices of fundamental science, and in the context of rapid changes, the processes of theory development are necessarily meshed tightly with realworld experimentation.

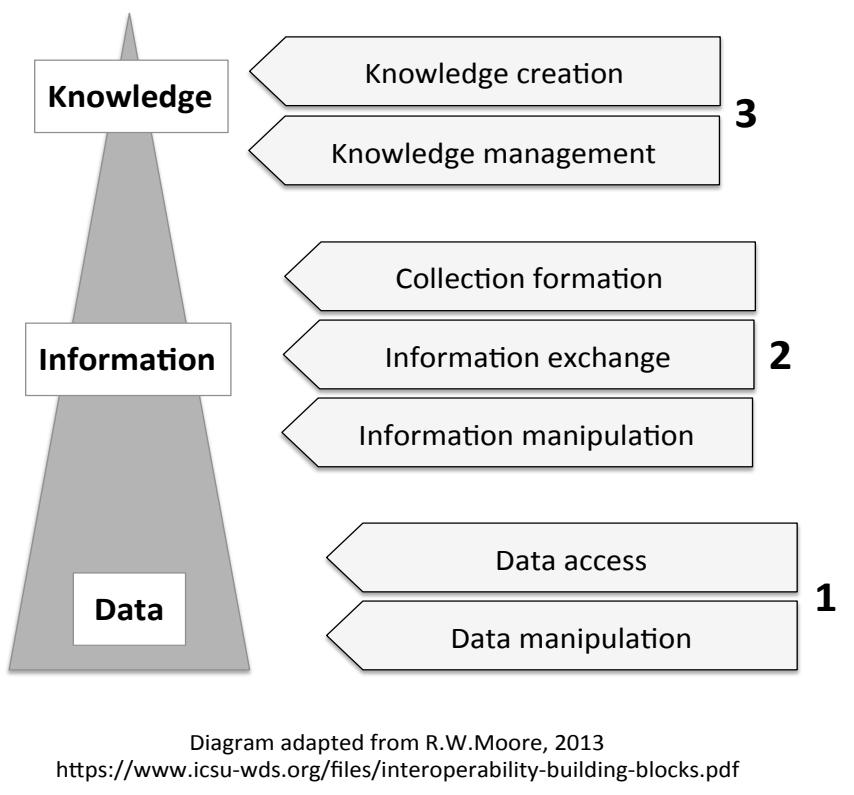

Figure 1 - The information hierarchy 


\section{Global environmental change is a domain where science and politics are inextricably linked}

The role of information, and the technical capacity to access and produce it, lies at the heart of sustainability, and it is a priority issue for international development cooperation ${ }^{3}$. The predictive power of global change science is increasingly called upon to inform pathways of societal development. The processes of information production and use are therefore tightly linked to issues of governance, economic development, and geopolitical power.

This creates new scientific responsibilities - and brings them under the spotlight, as social media discussions of climate change, biotechnologies, and new energy sources clearly show. The interface between science, policy and the rest of society is complex. It is however essential to keep track of this network of stakeholders ${ }^{3}$ to maintain the quality infrastructure for global change knowledge.

In this report, we address the quality infrastructure in global environmental change science and science-policy communication, primarily taking a research perspective. We consider a set of priority global change issues (using the planetary boundaries framework ${ }^{4}$, discussed in section 2), and focus on the state of knowledge within the following areas:

Understanding Earth system processes - the capacity for basic research underpinning global change science and policy.

Establishing assessment and prediction capacities - the scaling up of research to the global level, together with transdisciplinary integration, enabling description of the actual state and trends of the environment.

Responding effectively to environmental changes - the measures needed to implement targeted environmental management interventions, and the assessment of their effectiveness.

Providing appropriate information stewardship - the capacity for societal learning and knowledge co-development, including long-term information curation, participatory processes, and horizon-scanning for emergent environmental issues.

This sequence excludes a very broad range of real-world implementation issues that are very important concerns for society at large, but where the environmental research community plays a more marginal role. A review of the quality infrastructure from the perspective of the stakeholders at the policy and practice end of the knowledge 'pipeline' is beyond the scope of this report. Here, it is sufficient to say that:

- the extent and quality of the global change evidence base is sufficient to show the need for concerted action towards sustainability,

- many of the sustainability governance and implementation institutions have highly effective quality management approaches at the heart of their operations, and

- the interface between the global change research community and these policy and practice communities is under continual active discussion and development.

Table 1 highlights some reports, from beyond the research context and with a European and global perspective, that address particularly relevant aspects of the quality infrastructure for global sustainability.

\footnotetext{
${ }^{3}$ For instance, European Commission (2011) International cooperation in science, technology and innovation: Strategies for a changing world, Report of the Expert Group established to support the further development of an EU international STI cooperation strategy, http://ec.europa.eu/research/iscp/pdf/publications/report-inco-web-4.pdf.

4 The Planetary Boundaries concept was developed by an international group of global change experts. The main document is Rockström, J. et al. (2009). Planetary Boundaries: Exploring the Safe Operating Space for Humanity. Ecology and Society 14(2): 32, www.ecologyandsociety.org/vol14/iss2/art32. A companion article was published in the journal Nature, with invited commentaries from other experts: Rockström, J et al. (2009) A safe operating space for humanity. Nature 461: 472-475.
} 
Table 1 - Some information resources on quality infrastructure for global sustainability policy

\section{Education, scholarship and qualifications}

European Commission (2014)

Report on progress in Quality

Assurance in Higher Education.

European Union (2011) Directive amending Directive 2005/36/EC on the recognition of professional qualifications. PECONS 57/13

UNESCO/OECD (2005) Guidelines for quality provision in crossborder Higher Education.

World Bank/UNESCO Global Initiative for Quality Assurance Capacity (now in third grant period).

\section{Data consolidation}

UN Statistical Commission (2012) Report of the Secretary-General on national quality assurance frameworks.

Eurostat (2012) Quality Assurance Framework of the European Statistical System.

\section{Oversight capacity for monitoring and evaluation}

UN Environment Programme (2014) Medium-term strategy 2014-2017. (Section 5: Business strategy)

UN Development Programme (2012) Programme and operations policies and procedures. (Section: Results and accountability)

MDG Task Force/OPM: Carraro et al. (2004) Monitoring the Millennium Development Goals. OINIT 2012-EN.PDF http://ec.europa.eu/education/policy/highereducation/doc/quality_en.pdf

http://register.consilium.europa.eu/doc/srv?|=EN\&f=PE\%2057\%202013\%2

http://unesdoc.unesco.org/images/0014/001433/143349e.pdf

www.unesco.org/new/en/education/themes/strengthening-educationsystems/higher-education/quality-assurance/giqac

http://unstats.un.org/unsd/statcom/doc12/2012-13-NQAF-E.pdf; see also work in progress on methods:

https://unstats.un.org/unsd/pubs/gesgrid.asp?method=meth

http://epp.eurostat.ec.europa.eu/cache/ITY_PUBLIC/QAF_2012/EN/QAF_

www.unep.org/gc/gc27/download.asp?ID=4119 and www.unep.org/QAS

https://info.undp.org/globl/popp/rma/Pages/introduction.aspx 


\section{Challenges for analysis}

One aspect that is both important and very difficult to scope is the state of global coverage of a quality infrastructure for a particular issue. This report makes a preliminary and partial assessment for key environmental issues, by highlighting some significant initiatives of different kinds in each field.

The initiatives are displayed in a consistent form for each planetary boundary issue, using a cross-scale diagram of the type shown in Figure 2. This is intended to be an indicator of the coverage of information and the existence of processes for obtaining and disseminating it; it is not a comprehensive overview.

Measurement and quality aspects underpin fundamental and applied research, and have profound implications for the effectiveness of interventions in environmental processes. However, users of global change information at the different stages of the research to policy process frequently lack clear information about the norms and processes for measurement, standardization, conformity and compliance with standards, and the overall quality management process at each stage.

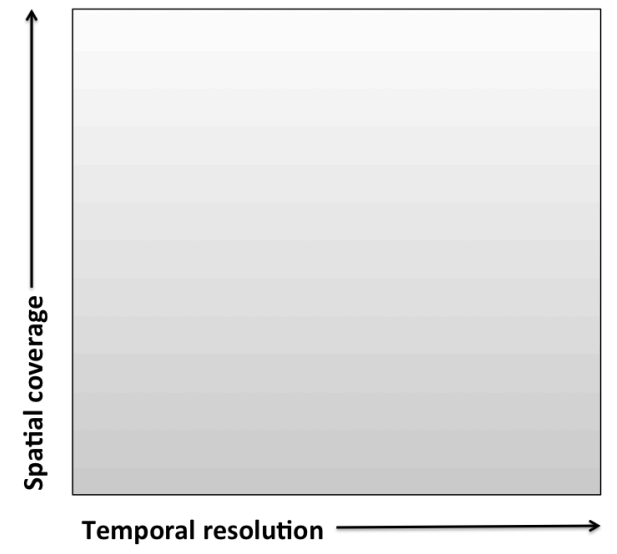

Figure 2 - Displaying the cross-scale coverage of global change information

The general characteristics of available global change information, including informal and formal (statutory) requirements for quality assessment, assurance and control, differ along the research-topractice sequence. At various stages, information is subject to different requirements for internal checks (standardization and technical regulation, which happens largely within the research community) and external checks (e.g., testing, accreditation and verification, which tends to happen at the research-policy-practice interface). Regulatory requirements also differ greatly among different global change processes. This has long been recognized as problematic, and has frequently led to calls for quality infrastructure improvement (table 2). Even those issues that have been recognized as urgent policy concerns have severe knowledge gaps.

In this report, we highlight some persistent quality challenges affecting the most pressing presentday global environmental change problems. We also describe efforts to overcome them, flagging examples of good practice that have been established in the recent decades. 
Table 2 - 40 years of calls for quality infrastructure improvement for global environmental change

\begin{tabular}{|c|c|}
\hline $\begin{array}{l}\text { 1975: US National Academy of Sciences } \\
\text { Committee on Data Interchange and Data Centers, } \\
\text { An assessment of the impact of the ICSU World } \\
\text { Data Centers on geophysics. (US NRC version } \\
\text { available on } \\
\text { http://books.google.se/books?id=8kErAAAAYAAJ) }\end{array}$ & $\begin{array}{l}\text { 'Many researches would have been impossible to } \\
\text { undertake in the absence of World Data Center data } \\
\text { collections. Availability of WDC data is particularly helpful } \\
\text { in assisting scientists in less technologically developed } \\
\text { countries'. }\end{array}$ \\
\hline $\begin{array}{l}\text { 1987: World Commission on Environment and } \\
\text { Development, Our Common Future ('The } \\
\text { Brundtland Report ') www.un- } \\
\text { documents.net/wced-ocf.htm }\end{array}$ & $\begin{array}{l}\text { 'The creation and enhancement of the infrastructure for } \\
\text { research and technology is a precondition for cooperation' } \\
\text { (para. 71). }\end{array}$ \\
\hline $\begin{array}{l}\text { 1990: National Environmental Satellite, Data and } \\
\text { Information Service, Data Management For Global } \\
\text { Change-current references. } \\
\text { http://docs.lib.noaa.gov/noaa_documents/NESDIS } \\
\text { /NODC/LISD/Central_Library/current_references/c } \\
\text { urrent_references_90-2.pdf }\end{array}$ & $\begin{array}{l}\text { This literature compendium references } 107 \text { articles (1985- } \\
\text { 1990), addressing data systems and practices in various } \\
\text { global change research contexts. } \\
\text { 'Some of the principal concerns surrounding global change } \\
\text { research and the computer industry include: data } \\
\text { management and accessibility, data integrity and security, } \\
\text { data storage, and computer power requirements.' }\end{array}$ \\
\hline $\begin{array}{l}\text { 2003: Bretherton, F., The role, value and limits of } \\
\text { S\&T data and information in the public domain: } \\
\text { Earth and Environmental sciences, in the } \\
\text { Proceedings of the Symposium on The Role of } \\
\text { Scientific and Technical Data in the Public Domain. } \\
\text { (US NRC version available on } \\
\text { http://books.google.se/books?id=OULvaEq8YFoC) }\end{array}$ & $\begin{array}{l}\text { 'Publicly-funded, shared-use, long-term observational } \\
\text { information is essential for sound public policy concerning } \\
\text { human interactions with the natural environment (...) Not a } \\
\text { single (environmental system) includes a recognizable } \\
\text { mechanism by which the different stakeholders can } \\
\text { actually get together and work out mutually satisfactory } \\
\text { win-win situations. That needs to be established.' }\end{array}$ \\
\hline $\begin{array}{l}\text { 2011: International Council for Science (ICSU) Ad } \\
\text { Hoc Strategic Coordinating Committee on } \\
\text { Information and Data, Interim Report. } \\
\text { www.icsu.org/publications/reports-and- } \\
\text { reviews/strategic-coordinating-committee-on- } \\
\text { information-and-data- } \\
\text { report/SCCID_Report_April_2011.pdf }\end{array}$ & $\begin{array}{l}\text { 'Adoption of a systematic standards-based approach to } \\
\text { data management will require significant cultural changes } \\
\text { in the ICSU family, and leadership by ICSU. There is a need } \\
\text { to understand better the range of data standards used and } \\
\text { how they interrelate. Neither ICSU nor its data } \\
\text { organisations specifies a standard framework and } \\
\text { governance for development and definition of standards.' }\end{array}$ \\
\hline $\begin{array}{l}\text { 2012: UN Environment Programme, Global } \\
\text { Environment Outlook 5, Chapter } 8 \text {. } \\
\text { www.unep.org/geo/pdfs/geo5/GEO5_report_c8.p } \\
\text { df }\end{array}$ & $\begin{array}{l}\text { 'Global research programmes are informing the debate } \\
\text { about present and future environmental challenges. } \\
\text { Nevertheless, deficiencies in scientifically credible data on } \\
\text { the environment (...) are a major handicap in developing } \\
\text { evidence-based policies.' }\end{array}$ \\
\hline
\end{tabular}

\section{A quality infrastructure for sustainability science and policy}

Quality infrastructure plays a key role in sustainable development, but one that is often unseen and undervalued. The seminal Brundtland report ${ }^{5}$ says 'sustainable development aims to promote harmony among human beings and between humanity and nature'. It specifies that achieving this requires a multifaceted integration of:

- a political system that secures effective citizen participation in decision making,

- an economic system that is able to generate surpluses and technical knowledge on a self-reliant and sustained basis,

- a social system that provides for solutions for the tensions arising from disharmonious development,

- a production system that respects the obligation to preserve the ecological base for development,

- a technological system that can search continuously for new solutions,

- an international system that fosters sustainable patterns of trade and finance, and

- an administrative system that is flexible and has the capacity for self-correction.

\footnotetext{
${ }^{5}$ World Commission on Environment and Development (1987) Our Common Future, A/42/427. Chapter 2 - The concept of Sustainable Development. www.un-documents.net/ocf-02.htm.
} 
It is evident that all these systems are intimately linked. All must address complex issues of measurement, compliance and quality management. Quality infrastructure is thus a general condition for sustainable development.

In this report, we focus specifically on issues in global environmental change research and policy. On one side, there is a need for quality infrastructure in all the sciences of global change, enabling effective interdisciplinarity and integration of knowledge across fields. On the other side, quality infrastructure underpins the role of this integrated knowledge in society's choices and actions for sustainability. Because of this scope, most of our discussion addresses the quality infrastructure in the technological system, but we must emphasise the importance of its interfaces with the political, social and international systems as an essential aspect of sustainable development.

Our focus is on the global level of sustainability science and policy, while recognizing that the vast majority of knowledge, choices and action relate to local, regional and national levels. In the remainder of this report, we address the state of global knowledge and its underlying quality infrastructure for a set of global environmental change priorities (section 2); we describe the means by which global environmental change and its associated risks are assessed (section 3); and we reflect briefly on ways that resilient responses can be developed, in light of rapid change and high uncertainty (section 4). Before doing that, however, we set out a few tenets that shape these discussions and inform our choice of experience examples in the remainder of the report:

\section{- Global sustainability requires global knowledge}

Participation in the development and use of global data and information needs to be a worldwide activity. A quality infrastructure enables improved worldwide information coverage, and helps to provide the conditions for the fair and inclusive integration of all countries into the sustainability policy system. It can redress the current situation, where both research and political negotiations for sustainability are often lopsided because of technical and institutional weakness or unpreparedness and a lack of information.

\section{- Global sustainability requires effective responses to global risks}

Precaution is needed in the face of the emerging risks that are associated with rapid environmental change. Precaution implies a greater emphasis on monitoring, improved ways to maximize the use and value of available data, and the development of analysis and response methods that are capable of accommodating great complexity. It also requires the establishment of enabling institutional environments at a national level in all countries, for effective responses to these emergent global risks.

\section{- Global sustainability entails living with uncertainty}

Provisionality in this context means acting with the knowledge that the measures taken may need to be changed (or halted, or reversed) in the light of new information. It is a vital feature both of science and of adaptive governance. Even in situations where there is a large amount of high-quality information about environmental processes, there are likely to be many sources and kinds of uncertainty. With a precautionary and provisional approach, inputs of new information are actively sought from a much wider range of sources. For global sustainability, this implies the creation of improved forums for discussion at all stages of the research-to-practice pipeline, and engaging a much broader swathe of society in these discussions. 


\section{The planetary boundaries: a dashboard for "strong sustainability"}

\section{Living in the Anthropocene}

A growing body of scientific evidence points at critical thresholds, or 'tipping points' in the functioning of the Earth system ${ }^{6}$. Crossing these thresholds leads to fundamentally different configurations of Earth's physical and ecological dynamics. This disrupts the structures and processes of the world's ecosystems, which provide beneficial but often unrecognised 'services' on which humanity fundamentally depends. These ecosystem services ${ }^{7}$ include processes like climate regulation, the maintenance of genetic diversity of life, the decomposition and detoxification of waste, and the vital functions of the water and nutrient cycles. Ecosystems also play an obviously crucial role in the provision of essential resources such as food, fibre and fuels. Abrupt shifts to new environmental states therefore challenge society's capacity to respond and adapt.

Awareness is growing about the ways in which human activities increase the risks of crossing these planetary thresholds, raising prospects of undesirable and potentially catastrophic consequences for society. Human-caused environmental changes are already pushing beyond Earth's 'safe operating space'.

A consensus already exists on the urgent planetary priorities for concerted action (Table 3): humancaused climate change, biodiversity loss, the alteration of key nutrient cycles (principally nitrogen $(\mathrm{N})$ and phosphorus (P)), and the release of chemical pollution into the atmosphere, land and water systems.

These processes are profoundly interlinked, cascading across time and space scales and disrupting local and regional flows of ecosystem services. Their impacts are escalating worldwide, while the human pressures - due to a combination of population growth, rising levels of consumption, and greater technological capabilities - are still growing.

Table 3 - Science and policy assessments of global environmental change priorities

(Table adapted from a compilation in Elmqvist, T. et al. (2014), Global Sustainability \& Human Prosperity. Nordic Council of Ministers, http://dx.doi.org/10.6027/TN2014-527.)

\begin{tabular}{|c|c|c|}
\hline Global priorities & Global assessments and evidence sources & Policy structures \\
\hline $\begin{array}{l}\text { Climate change } \\
\text { Social impacts include } \\
\text { health, changes in } \\
\text { environmental hazards } \\
\text { and risks, reduced food } \\
\text { and water security } \\
\text { Biophysical impacts } \\
\text { include ocean } \\
\text { acidification, ecosystem } \\
\text { change, sea-level rise and } \\
\text { altered coastal } \\
\text { environments }\end{array}$ & $\begin{array}{l}\text { IPCC Assessment Reports 1990, 1995, 2001, 2007, } \\
\text { 2013/14. www.ipcc.ch } \\
\text { IPCC WG I and II (2012) Managing the risks of extreme } \\
\text { events and disasters. CUP. } \\
\text { UN HDR (2007/8) Fighting climate change: Human } \\
\text { solidarity in a divided world. } \\
\text { http://hdr.undp.org/en/reports/global/hdr2007-8. } \\
\text { Many regional impact assessments (e.g., EEA, Arctic). } \\
\text { Gattuso J.-P. \& Hansson L. (Eds.), Ocean acidification, pp. } \\
\text { 122-153. OUP. } \\
\text { European Project on Ocean Acidification: www.epoca- } \\
\text { project.eu/index.php/what-do-we- } \\
\text { do/science/publications.html }\end{array}$ & $\begin{array}{l}\text { IPCC and UNFCCC SBSTA are } \\
\text { scientific policy forums. } \\
\text { Global and supranational } \\
\text { governance for climate change } \\
\text { includes: UNFCCC, Kyoto Protocol; } \\
\text { Vienna Convention, Montreal } \\
\text { Protocol; UNECE CLRTAP. } \\
\text { Emerging policy response to } \\
\text { ocean acidification (indirectly } \\
\text { addressed by UNFCCC } \mathrm{CO}_{2} \\
\text { mitigation measures). } \\
\text { See: http://unfccc.int/timeline }\end{array}$ \\
\hline
\end{tabular}

${ }^{6}$ The Earth system is a scientific conceptualisation of the whole planet as a complex interacting system, with living and non-living components. See www.igbp.net/globalchange/earthsystemdefinitions, and Cornell et al. (2012) Understanding the Earth System: global change science for application. CUP, Cambridge.

7 TEEB (2010), The Economics of Ecosystems and Biodiversity: Mainstreaming the economics of nature. A synthesis of the approach, conclusions and recommendations of TEEB, www.teebweb.org; Millennium Ecosystem Assessment (2005) Ecosystems and human well-being: Synthesis. Island Press. www.maweb.org. 


\begin{tabular}{|c|c|c|}
\hline Global priorities & Global assessments and evidence sources & Policy structures \\
\hline $\begin{array}{l}\text { Ecosystem change and } \\
\text { biodiversity loss } \\
\text { Ecosystem services are } \\
\text { lost, with impacts on food } \\
\text { security, water quality, } \\
\text { environmental hazards, } \\
\text { fuel/fibre resources, and } \\
\text { many regulating services } \\
\text { and cultural benefits. }\end{array}$ & $\begin{array}{l}\text { Millennium Ecosystem Assessment (2005) Biodiversity } \\
\text { and human wellbeing: current states and trends. Island } \\
\text { Press. } \\
\text { IPBES Sub-Global Assessments repository, } \\
\text { http://ipbes.unepwcmc-004.vm.brightbox.net } \\
\text { CBD (2010) Global Biodiversity Outlook 3. } \\
\text { www.cbd.int/gbo3 } \\
\text { TEEB (2010) Ecological and economic foundations. The } \\
\text { Economics of Ecosystems and Biodiversity. Island Press. } \\
\text { UNEP (2012) Global Environment Outlook 5: } \\
\text { Environment for the future we want. UN Environment } \\
\text { Programme, Nairobi, Kenya. } \\
\text { FAO reports: } \\
2010 \text { - The state of the world's plant genetic } \\
\text { resources. } \\
\text { www.fao.org/docrep/013/i1500e/i1500e00.htm } \\
2010 \text { - The Global Forest Resources Assessment. } \\
\text { www.fao.org/forestry/fra/en/ } \\
2012 \text {-The State of Food and Agriculture (SOFA). } \\
\text { www.fao.org/publications/sofa/en } \\
2012 \text {-The State of the World Fisheries and } \\
\text { Aquaculture (SOFIA). www.fao.org/fishery/sofia/en }\end{array}$ & $\begin{array}{l}\text { IPBES and CBD SBSTTA are } \\
\text { scientific policy forums. } \\
\text { Global and supranational } \\
\text { governance for biodiversity and } \\
\text { ecosystem change includes: CBD, } \\
\text { CITES, Ramsar, Bonn and Bern } \\
\text { Conventions. } \\
\text { See: www.cbd.int/ecolex }\end{array}$ \\
\hline $\begin{array}{l}\text { Alteration of essential } \\
\text { nutrient cycles ( } \mathbf{N} \text { and } \mathbf{P} \text { ) } \\
\text { Disturbed global nitrogen } \\
\text { and phosphorus cycles } \\
\text { cause major } \\
\text { environmental, health } \\
\text { and economic problems, } \\
\text { including soil nutrient } \\
\text { losses, air and water } \\
\text { pollution, and land and } \\
\text { ecosystem degradation. }\end{array}$ & $\begin{array}{l}\text { GPNM/INI, by Sutton M.A. et al. (2013). Our Nutrient } \\
\text { World: The challenge to produce more food and energy } \\
\text { with less pollution. CEH Edinburgh. Available from } \\
\text { www.unep.org } \\
\text { IMCO/FAW/ UNESCO/ WMO/IAEA/UN/UNEP, by } \\
\text { GESAMP (1990). The State of the Marine Environment. } \\
\text { GESAMP Reports and Studies No } 39 \text {. }\end{array}$ & $\begin{array}{l}\text { Several science-policy forums: } \\
\text { International Nitrogen Initiative; } \\
\text { Global Phosphorus Research } \\
\text { Initiative; UNEP-Global } \\
\text { Partnership on Nutrient } \\
\text { Management; WHO; FAO; WMO, } \\
\text { IPCC; Regional seas (e.g., Arctic } \\
\text { Council). } \\
\text { Global governance includes } \\
\text { UNFCCC, CBD (e.g., Aichi Target } \\
\text { 8). Supranational governance } \\
\text { includes UNECE CLRTAP and } \\
\text { Water Convention, HELCOM } \\
\text { (Baltic nations, EU), OSPAR (North } \\
\text { Sea, NE Atlantic). }\end{array}$ \\
\hline $\begin{array}{l}\text { Chemical pollution } \\
\text { Direct human health } \\
\text { impacts; indirect impacts } \\
\text { through perturbed } \\
\text { ecological and physical/ } \\
\text { climatic functioning. } \\
\text { Particular concern over } \\
\text { toxic, bioaccumulative, } \\
\text { persistent and } \\
\text { environmentally } \\
\text { transportable substances. } \\
\text { CFC-induced stratospheric } \\
\text { ozone depletion is a } \\
\text { particular instance of } \\
\text { human activities } \\
\text { approaching a planetary } \\
\text { threshold. }\end{array}$ & $\begin{array}{l}\text { UNEP (2013) Global Chemicals Outlook } \\
\text { www.unep.org/pdf } \\
\text { UNEP (2013) Costs of inaction on the sound } \\
\text { management of chemicals. } \\
\text { www.unep.org/hazardoussubstances/UNEPs- } \\
\text { Work/Mainstreaming/ CostsofInactionInitiative } \\
\text { AMAP (2009) Arctic Pollution 2009. Arctic Monitoring } \\
\text { and Assessment Program, http://amap.no } \\
\text { Depledge M, et al. (2013) Are marine environmental } \\
\text { pollutants influencing global patterns of human disease? } \\
\text { Marine Environmental Research 83, 93-95. }\end{array}$ & $\begin{array}{l}\text { Science policy forums include } \\
\text { SETAC, SCI and the WHO } \\
\text { Intergovernmental Forum on } \\
\text { Chemical Safety. } \\
\text { International environmental } \\
\text { agreements exist but do not cover } \\
\text { all substances of concern. IEAs } \\
\text { include the Stockholm Convention } \\
\text { and CLRTAP. } \\
\text { The UNEP Ozone Secretariat APs } \\
\text { are a key science-policy forum. } \\
\text { Global governance of the ozone } \\
\text { problem is through the Vienna } \\
\text { Convention, and its Montreal } \\
\text { Protocol. }\end{array}$ \\
\hline
\end{tabular}




\section{The planetary boundaries - a concept in development}

The planetary boundaries concept was developed as a research agenda-setting framework to address these multiple processes together. It seeks to define critical Earth system processes that regulate the stability of the world's ecosystems, and indeed the Earth system as a whole. In addition to the global priority issues described in Table 3, Rockström and colleagues included land use, freshwater use and the atmospheric aerosol burden as global processes for which planetary boundaries should be set. These are also issues where there has been extensive human perturbation, but at present there is no global-level policy goal, and the scientific rationale for the actual position of these boundaries is still being debated and developed.

The current reality is that both science and policy tend to treat these issues separately, even though they are known to be linked in multiple and complex ways. Research and debate therefore continues in this new area of integrative global change science. In the five years since Rockström and colleagues published the first article, several research groups have sought to improve our understanding of biophysical planetary thresholds and to inform precautionary decisions about where 'safe operating boundaries' should be set (Box 1).

\section{Box 1 - Recently published discussions of the planetary boundaries concept and related research}

Proposed refinements to the planetary boundaries include new approaches to defining boundaries for phosphorus (Carpenter and Bennett 2011), nitrogen (de Vries et al. 2013), freshwater use (Rockström and Karlberg 2010, Gerten et al. 2013), and chemical pollution (Handoh and Kawai 2011, Persson et al. 2013). Barnosky et al. (2012) made an analysis of a state shift in the global biosphere, and Running (2012) suggests an integrative boundary linking land, water and terrestrial biodiversity, based on net primary productivity. All these studies provide evidence of systemic thresholds and biophysical regime shifts, arguing in favour of boundaries that set strong reductions in the current levels of anthropogenic perturbation.

Another area of research focuses on characterizing the Anthropocene - the new geological epoch defined by humanity's impact on the planet. Articles on this topic include Steffen et al. 2011, Zalasiewicz et al. 2011, and Crumley 2013. Raworth (2012) has extended the planetary boundary concept to social objectives, arguing for a 'safe and just operating space' for humanity.

Some work also explores how the planetary boundaries concept might be applied in practice, at different geographical scales and in different sectoral contexts: Nykvist et al. 2013, Raworth 2012, Steffen and Stafford-Smith 2013, Biermann 2012, Galaz et al. 2012, Whiteman et al. 2012.

Finally, a rapidly developing area of work is addressing critical global thresholds or 'tipping points'. The best summary of the current science is in the IPCC's 2013 Fifth Assessment Report, Working Group I (The Physical Science Basis, available at http://www.climatechange2013.org/images/report/WG1AR5_Chapter12_FINAL.pdf, section 12.5).

\section{References:}

Biermann, F. (2012) Planetary boundaries and earth system governance: Exploring the links. Ecological Economics. 81: 4-9.

Carpenter, S. and Bennett, E. (2011) Reconsideration of the planetary boundary for phosphorus. Environmental Research Letters. doi: 10.1088/1748-9326/6/1/014009

Crumley, C. (2013). New Paths into the Anthropocene. Oxford Handbook of Historical Ecology, C. Isendahl and D. Stump, eds. OUP. de Vries, W. et al. (2013) Assessing planetary boundaries related to food security and adverse environmental impacts. COSUST 5: 392-402 Galaz, V. et al. (2012) "Planetary boundaries" - exploring the challenges for global environmental governance. COSUST 4: 80-87. Gerten, D. et al. (2013) Towards a revised planetary boundary for consumptive freshwater use. COSUST 5, 551-558.

Handoh, I. and Kawai, T. (2011) Bayesian uncertainty analysis of the global dynamics of persistent organic pollutants: towards quantifying the planetary boundaries for chemical pollution. In: ISEC - Marine Environmental Modeling \& Analysis, Eds. K. Omori, et al., pp. 179-187. Nykvist, B. et al. (2013) National Environmental Performance on Planetary Boundaries. Swedish Environmental Protection Agency

Persson, L. et al. (2013) Confronting unknown planetary boundary threats from chemical pollution. Environmental Science \& Technology. www.ncbi.nlm.nih.gov/ pubmed/23980998

Raworth, K. (2012). A Safe and Just Operating Space for humanity: Can we live within the doughnut? Oxfam Discussion Papers, Oxford. Steffen, W. and Stafford-Smith, M. (2013). Planetary boundaries, equity and global sustainability. COSUST 5: 1-6.

Steffen, W., et al. (2011) The Anthropocene: From global change to planetary stewardship. Ambio 40: 739-761.

Whiteman, G. et al. (2012) Planetary Boundaries: Ecological foundations for corporate sustainability. Journal of Management Studies, 50: 307-336.

Zalasiewicz, J. et al. (2010). The new world of the Anthropocene. Environmental Science \& Technology, 44: 2228-2231. 


\section{The planetary boundaries - absolute?}

The planetary boundaries concept explicitly builds on the Limits to Growth analysis ${ }^{8}$, 'tolerable windows' and 'guardrails' approaches', 'carrying capacity', and management concepts such safe minimum standards and critical loads.

At the same time, it differs fundamentally from these widely known sustainability concepts. These other concepts define a social entry point to their analysis (such as a desired state of economic, political or demographic conditions) and then seek to analyse the environmental impact.

The planetary boundaries concept started with an attempt to identify which of the Earth's regulating processes maintain a climatically and ecologically stable Holocene-like state. The stability of the Holocene period has been a strong environmental factor allowing for the development of human civilization, settlement and agriculture. The quantifications of the planetary boundaries are not based on humanity's desires, but on Earth's intrinsic limits as a complex biophysical system.

It is evident that the planetary boundaries concept depends critically on the availability of a robust observational evidence base and a deep understanding of global dynamics and cross-scale interactions among multiple processes. The data required to study planetary boundaries extend far beyond just the measurement of the proposed boundary control variables. For instance, understanding, monitoring and mitigating climate change requires a broader set of variables than just $\mathrm{CO}_{2}$ concentrations and global radiative forcing.

In the following sections, we briefly summarise the state of the planetary boundary issues, and of the global capacity for understanding and quantifying the processes. It will become clear that different global change processes face very different quality infrastructure concerns. Some have very mature science, policy and science-policy-practice infrastructures, while others do not.

This report cannot deal comprehensively with all these issues. We aim to identify both shared themes and the distinctive features of each field, and we provide pointers to places where the main stakeholders in the research-to-practice continuum address quality infrastructure issues.

\footnotetext{
${ }^{8}$ Meadows, D.H. et al. (1972), The limits to growth. Universe Books, New York; Meadows, D. et al. (2004). Limits to growth: the 30year update. Chelsea Green, White River Junction VT.

${ }^{9}$ For example, Petschel-Held, G., et al. (1999), The tolerable windows approach Climatic Change 41, 303-331; and Bruckner, T. et al. (1999), Climate change decision support and the tolerable windows approach. Environmental Modeling and Assessment 4, 217-234
} 


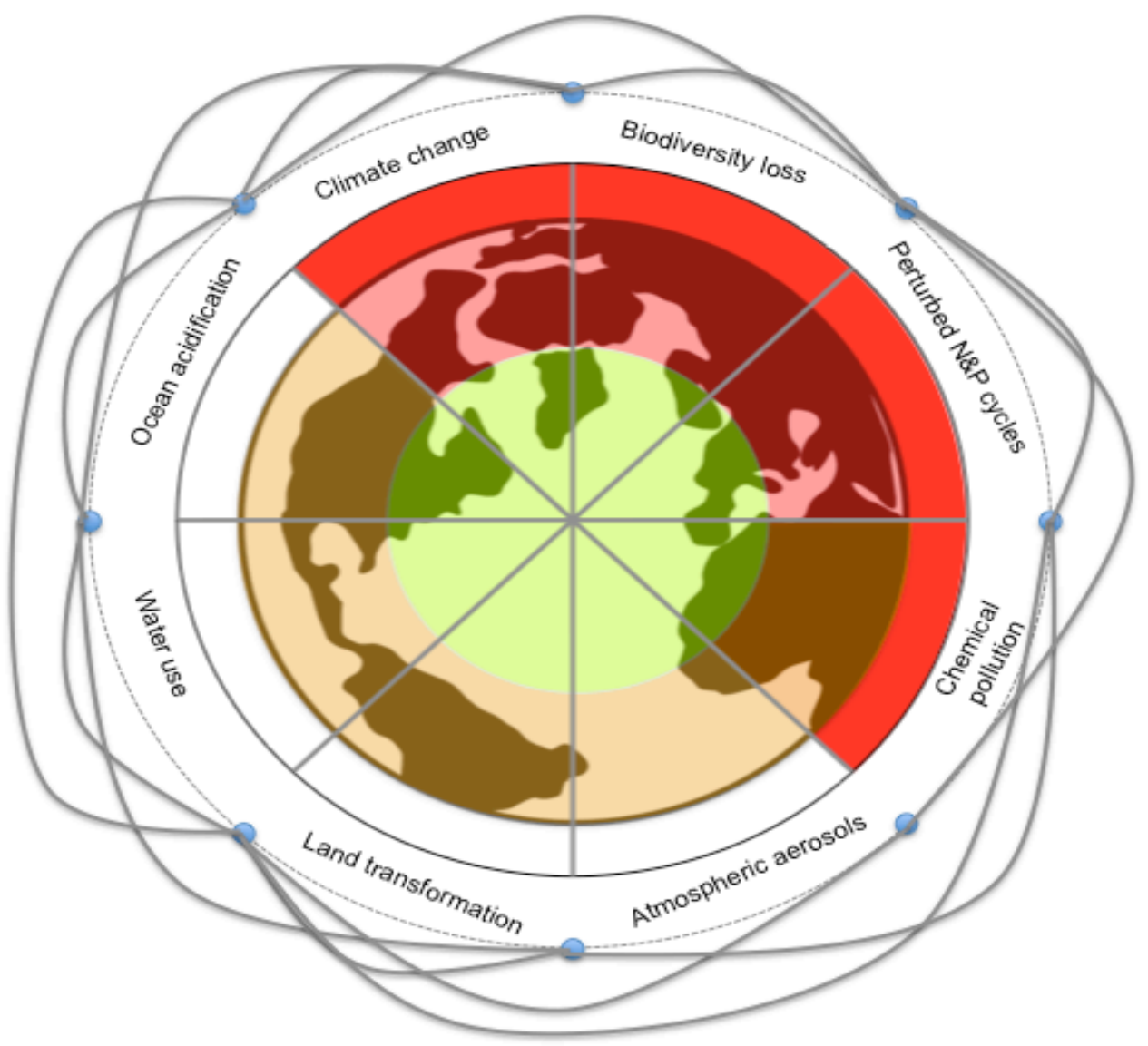

Figure 3 - Scientific consensus is that human activities have already pushed several global processes to levels where risks of crossing planetary thresholds are increased. (Diagram based on Rockström et al. 2009 and more recent research, outlined in this report.)

\section{Climate Change}

Carbon dioxide plays a vital role in many global biogeochemical processes (that is, processes that involve living organisms). Important carbon processes are photosynthesis, respiration, the decay of organic matter, biological carbon sequestration on land and in the oceans, and the maintenance of seawater $\mathrm{pH}$. Ocean acidification worsens in step with rising atmospheric $\mathrm{CO}_{2}$. These processes all interact in complex ways with the physical climate, which is also affected directly by the present levels of human-caused $\mathrm{CO}_{2}$ emissions through the greenhouse effect.

Other greenhouse gases also affect physical climate (and require mitigation action by society), but climate stabilisation - at any desired level - demands cuts in human-caused emissions of $\mathrm{CO}_{2}$, because of its functions in the biosphere. The dynamics and feedbacks of the carbon cycle mean that a significant portion of present-day $\mathrm{CO}_{2}$ emissions will stay in the atmosphere for thousands of years. We are making effectively irreversible changes to the Earth system.

Addressing the overall carbon budget matters fundamentally for climate ${ }^{10}$, and climate impacts increase with rising concentrations of $\mathrm{CO}_{2} \cdot{ }^{11}$ This is why the global $\mathrm{CO}_{2}$ concentration is a key 'control variable'.

\footnotetext{
${ }^{10}$ Anderson, K. and Bows, A. (2008) Reframing the climate change challenge in light of post-2000 emission trends. Philosophical Transactions of the Royal Society, A 366 (1882), 3863-3882, http://rsta.royalsocietypublishing.org/content/366/1882/3863.long

${ }^{11}$ Intergovernmental Panel on Climate Change, Working Group II Impacts, Adaptation and Vulnerability. The Fifth Assessment Report was published in 2014: http://ipcc-wg2.gov/AR5
} 
Rockström and colleagues proposed a boundary level of 350 parts per million of $\mathrm{CO}_{2}$ in the atmosphere (together with a net increase in radiative forcing of no more than $+1 \mathrm{~W} \mathrm{~m}^{-2}$, which would provide a high likelihood of remaining within the policy goal of 2 degrees of global warming ${ }^{12}$. They also proposed a boundary for ocean acidification, sustaining $\geq 80 \%$ of the pre-industrial carbonate saturation (aragonite form) of the surface ocean.

\section{The current state ${ }^{13}$}

The atmospheric concentration is currently $\sim 396 \mathrm{ppm} \mathrm{CO}$, depending on the point in the annual cycle. The 1990 concentration was $\sim 350 \mathrm{ppm}$; globally agreed climate targets correspond to a maximum of $450 \mathrm{ppm}$.

Concentrations are rising by $\sim 2 \mathrm{ppm}$ per year, pointing to exceeding $450 \mathrm{ppm}$ concentration in just $\sim 30$ years. Current emissions are $\sim 35 \mathrm{Gt} \mathrm{CO} 2$ per year, rising globally at 3-5\% per year. Stabilising $\mathrm{CO} 2$ concentration means reducing emissions essentially to zero.

Ocean acidification is tightly linked to climate change, as it is also driven by $\mathrm{CO}_{2}$ emissions to the atmosphere. The current carbonate saturation state of the mean surface ocean is 2.9 , relative to the pre-industrial value of 3.4 , and the proposed boundary of 2.75 .

\section{Links to freshwater use, land use, and the atmospheric aerosol burden $^{14}$}

Water systems are very sensitive to climate change. Climate changes geographic patterns of supply (both drought and flooding). Water-stressed ecosystems and social systems can alter climate feedbacks leading to abrupt or irreversible change. Climate also has indirect effects on water quality, so there are important links to the planetary boundary processes for the biogeochemical cycles of nutrient elements, and the release of chemical pollution. Land use change is a key driver of climate change through many mechanisms. These include carbon emissions from deforestation and soil degradation, albedo changes associated with land cover change, and effects linked to vegetation changes, including changed water cycling (for example, transpiration from forests is higher than from savannah) and altered patterns of atmospheric aerosol formation (a significant proportion of aerosol is formed naturally in the atmosphere from volatile organic compounds given off by vegetation).

\section{The quality infrastructure for climate change}

Global concern about climate change means that there is now a very extensive and complex global infrastructure for understanding and responding to climate change. Figure 4 gives an indication of the spatial and temporal coverage of different kinds of climate change data and information ${ }^{15}$.

\footnotetext{
${ }^{12}$ Supporting analysis for Rockström and colleagues' proposed 350 ppm boundary level includes a probabilistic climate risk analysis by Harvey, L.D.D. (2007) Dangerous anthropogenic interference, dangerous climatic change, and harmful climatic change: non-trivial distinctions with significant policy implications, Climatic Change 82 (1-2), 1-25; a multi-measure palaeoclimate analysis, Hanson et al. (2008) Target Atmospheric $\mathrm{CO}_{2}$ : Where Should Humanity Aim? The Open Atmospheric Science Journal, 2, 217-231,

http://benthamscience.com/open/toascj/articles/V002/217TOASCJ.pdf. The IPCC AR5 WGI provides a comprehensive review of already-observed changes in extreme weather and climate events associated with the present-day levels of $\mathrm{CO}_{2}$ www.climatechange2013.org/images/report/WG1AR5_SPM_FINAL.pdf.

${ }^{13}$ Global Carbon Budget 2013, by the Global Carbon Project: www.globalcarbonproject.org/carbonbudget/index.htm

${ }^{14}$ IPCC WGII 2014, Impacts, Adaptation and Vulnerability, chapters 3 and 4: http://ipcc-wg2.gov/AR5; IPCC WGI 2013, The Physical Science Basis, chapters 6, 7 and 8: https://www.ipcc.ch/report/ar5/wg1.

${ }^{15}$ We use the term 'synoptic' to avoid confusion about what is 'regional' scale. Synoptic scale is of the order of $\sim 1000 \mathrm{~km}$ - the typical magnitude of weather patterns and biomes.
} 


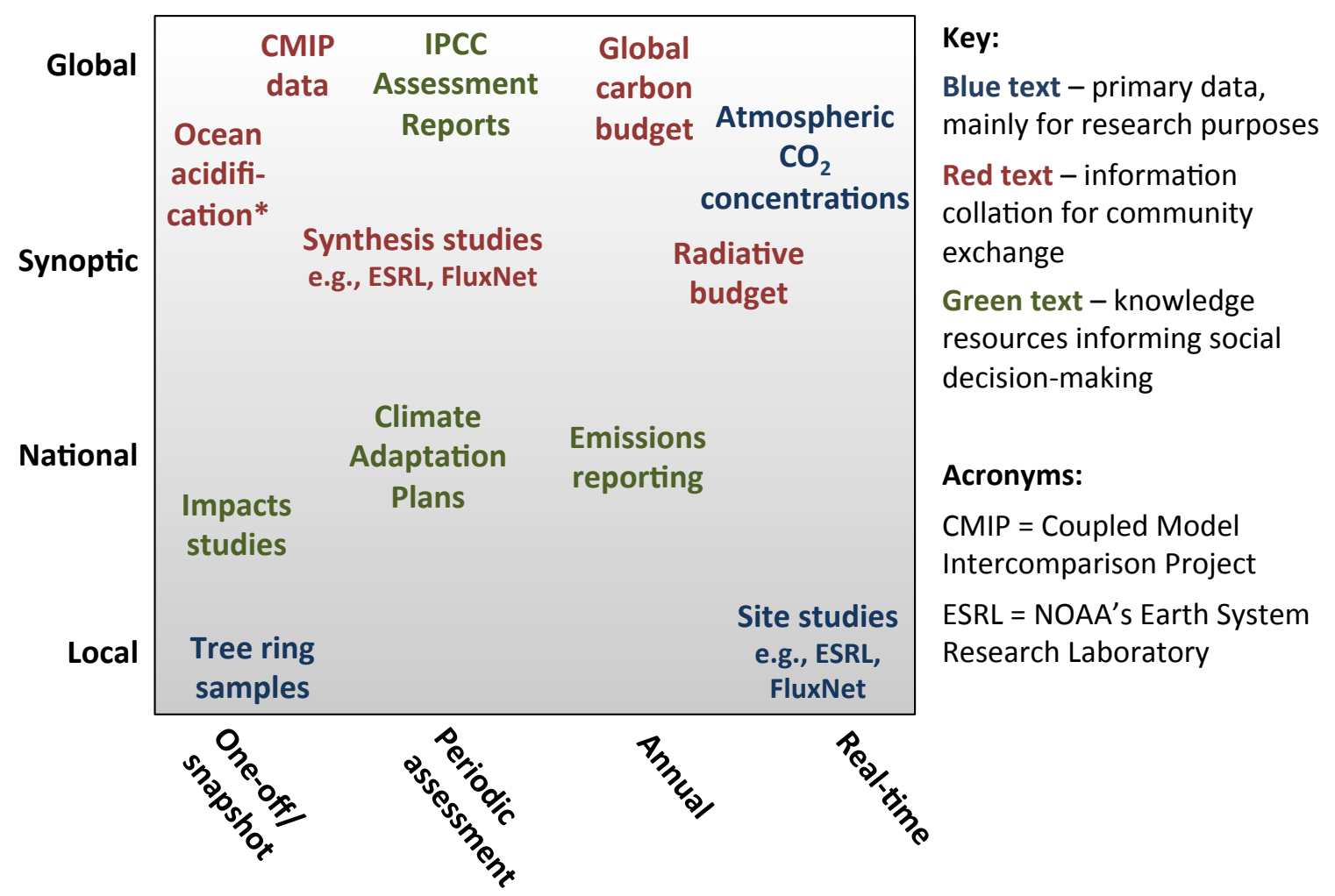

Figure 4 - The spatial and temporal coverage of climate change information.

(* See Box 2 for information on the emerging quality infrastructure for ocean acidification, one of the serious global biophysical impacts of climate change)

\section{Basic data - for research and policy}

There is an immense number of sources of basic data (corresponding to level 1 in Figure 1) underpinning present-day understanding of climate change and its impacts. These range from unique, locality-specific individually sampled data such as local ground temperature measurements, through to satellite images with pixel sizes several kilometers across. Carbon dioxide and many other greenhouse gases are globally well-mixed, so measurements in any location are representative of the whole globe. All other climate-related measures are globally heterogeneous, a feature that applies to most environmental processes.

In one important initiative for global coordination of this great diversity, the Global Climate Observing System has defined a set of 50 GCOS Essential Climate Variables

(https://www.wmo.int/pages/prog/gcos), covering key properties of atmosphere, oceans and land. These are the core data that underpin the UNFCCC and IPCC's research and policy assessments of the state of the climate, and form the basis of international information exchange. The GCOS list helps to shape the strategic priorities of researchers engaged in method development and measurement, and also of data providers, notably the Earth observation agencies ${ }^{16}$.

In general, the issues of data gathering and manipulation arise firmly in the domain of the fundamental research that enables understanding of Earth system processes. In many cases, a considerable amount of post-sampling analysis is needed to extract the required climatic variables from the raw data source, as in the case of tree rings, and the fossil shells of microorganisms (e.g., Foraminifera) collected from marine sediments.

\footnotetext{
${ }^{16}$ For example, the European Space Agency's Climate Change Initiative works closely with the Earth system science research community in improving products for the essential climate variables: www.esa-cmug-cci.org.
} 
Many methods are very well established and the research community has clearly documented processes and protocols to ensure quality, consistency and comparability. This enables the monitoring of climate change in highly efficient ways, given the global magnitude of the issue.

But this is also a field where there is a great deal of method development where these quality concerns need to be scrutinised and agreed by the expert community. For example, as models develop with higher resolution and more process complexity, new kinds of observations are needed to provide improved parameters for the models, and to quantitatively evaluate ('benchmark') models of multiple processes. Generally speaking, there are two distinct research communities dealing with modelling and model development on one hand, and experimental and empirical data on the other. The challenges of bridging these communities, with their particular research cultures and norms regarding quality and compliance, are well-recognised 17 .

In some cases, analytical methods are often still highly experimental. An interesting example is the development of new satellite data products ${ }^{18}$. Raw standard binary satellite data will have undergone routine quality checks (calibration, geo-location, atmospheric correction, registration, etc.). Derived products are really best regarded as a special category of model output. They undergo processes such as data merging, interpolation, and analytical transformation. Apart from requiring scientific scrutiny of the techniques, new products also require new metadata protocols that address issues such as the data quality and provenance.

\section{Meeting information needs - researching a changing world}

\section{Data networks}

Scientific coordination and synthesis of climatic data (i.e., information, level 2) is absolutely essential to the research process for climate change. Coordination efforts include the establishment of international networks for obtaining, compiling, archiving and distributing worldwide data. Good examples of global data synthesis efforts include:

- Exchanges of energy, water and carbon dioxide: FluxNet (http://fluxnet.ornl.gov), an international network that has particular importance in 'benchmarking' climate and carbon cycle models with observational data. FluxNet uses micrometeorological tower sites for measurements of important carbon cycle exchanges ${ }^{19}$ between the atmosphere and biosphere (plants and soil). The network began in Europe in the mid-1990s, and is now one of the best observational initiatives in climate science in terms of worldwide coverage and method development, evaluation and consistency. Since 2002 it has been part of the NOAA Global Observing System Architecture.

- Global palaeovegetation 'timeslices' and mapping: BIOME 6000 (www.ncdc.noaa.gov/paleo/biome6000.html) is a successful community-wide collaboration. Since $1994^{20}$ it has created fully-documented pollen and plant macrofossil data sets for 6000 and 18,000 years before present (i.e., the mid-Holocene warm period and the last glacial maximum). It has constructed standardised global maps of biomes for these time periods that can be used to evaluate Earth system model experiments.

\footnotetext{
${ }^{17}$ A good and still topical discussion is in Randall, D.A. and Wielicki, B.A. (1997) Measurements, Models, and Hypotheses in the Atmospheric Sciences. Bulletin of the American Meteorological Society, 78, 399-406. http://dx.doi.org/10.1175/15200477(1997)078<0399:MMOHIT>2.0.CO;2

18 Two useful books provide accessible overviews of these issues: Shoshani, A. and Rotem D. (2010). Scientific data management: Challenges, technology, and deployment, Chapman \& Hall (especially chapter 12); and Robinson, I.S. (2004) Measuring the oceans from space, Springer.

${ }^{19}$ An informative animation by the US National Parks Service of the carbon cycle processes of interest is available on http://en.wikipedia.org/wiki/File:Carbon_Cycle-animated_forest.gif

${ }^{20}$ For research information, see http://www.bridge.bris.ac.uk/projects/BIOME_6000/\#5 and Prentice, C.I. et al. (1996) Reconstructing biomes from palaeoecological data: a general method and its application to European pollen data at 0 and 6 ka. Climate Dynamics 12(3):185-194.
} 
- Global dust mapping: Dust Indicators and Records of Terrestrial and Marine Palaeoenvironments (DIRTMAP, www.bridge.bris.ac.uk/projects/DIRTMAP, data also lodged with NOAA) collates data for specific time-slices from ice cores, marine sediments, and terrestrial deposits. Dust is an important feedback in the Earth system, but it is still very poorly quantified and spatially resolved.

- Evolutionary and ecological research: TraitNet (http://traitnet.ecoinformatics.org) and TRY (www.try-db.org/index.php?n=Site.Database) have been building a global archive of plant traits. Using plant traits in a new generation of global vegetation models can improve the capacity for prediction of plant responses to climate change and ecosystem shifts (e.g., invasive species, extinction risk).

Coordination also includes the establishment of time-series data at particular sites. The most iconic of these is the Mauna Loa $\mathrm{CO}_{2}$ series ${ }^{21}$, which has tracked the accelerating atmospheric concentration since 1958. This started as a research activity, but has now become the foundation stone of a global climate monitoring activity in support of international policy and climate mitigation action.

A feature of many of these initiatives is that they are researcher-driven, often with no dedicated resourcing at the outset. They run on short-term 'soft money', which makes continuity breaks a constant risk. The sites, methods, and sampling often have to be selected opportunistically for logistical reasons, rather than strategically for scientific reasons. This means that even the best international cooperation examples have very patchy global coverage (Figure 5 shows the regional distribution of the approximately 450 NOAA-ESRL sites ${ }^{22}$ - note that about $40 \%$ of all the sites are in USA territory). Locations near to US and European research institutes are very well studied, while regions of the world expected to undergo the most rapid environmental changes (notably polar regions, arid regions, and the tropics) are extremely sparsely covered. Similarly, understanding the dynamics of global change self-evidently requires information about change over time, yet the reliance on ad hoc, pragmatic and often shoe-string approaches means we face a stark shortage of long time series 23 .

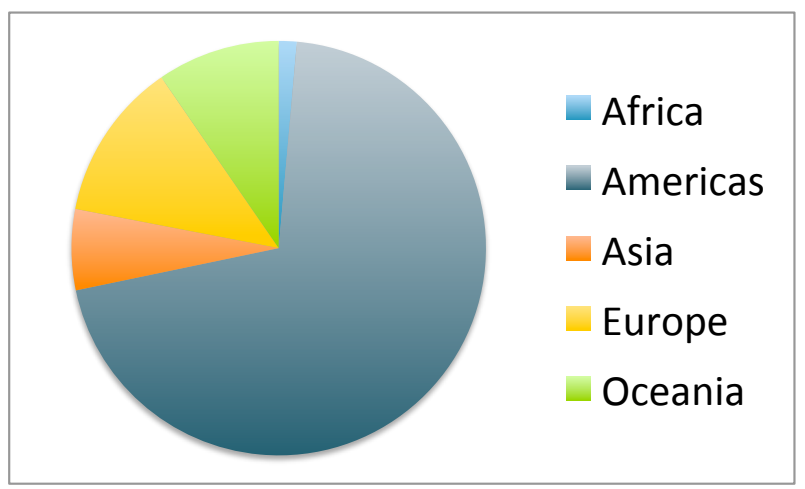

Figure 5 - The global distribution of NOAA-ESRL Global Monitoring Division climate and atmospheric chemistry observation sites (compiled with data from www.esrl.noaa.gov/gmd/dv/site/map1.html)

\section{Data coordination and sharing}

An important process in climate information coordination is the collation of different kinds of data (discussed in more detail in section 3). The US National Oceanic and Atmospheric Administration (NOAA) plays a globally critical role in this regard. Its Earth System Research Laboratory has the remit to 'observe and understand' the global biophysical system, bridging from pure research to societally relevant policy processes. ESRL hosts many of the research community's strategic coordination and quality infrastructure forums, including:

\footnotetext{
${ }^{21} \mathrm{http}: / /$ keelingcurve.ucsd.edu.

22 Note that this diagram excludes 38 oceanic (research vessel) observation sites.

${ }^{23}$ For example, Walstad, R. (2011) The data challenge for research and policy on weather, climate, and society. WCS 3, 69-70. http://journals.ametsoc.org/doi/pdf/10.1175/WCAS-D-11-00023.1
} 
- The NOAA Environmental Software Infrastructure and Interoperability Group (www.esrl.noaa.gov/nesii), which develops software to support global change research and operations, such as the US Earth System Modeling Framework.

- The Global Monitoring Division (www.esrl.noaa.gov/gmd, Figure 4) obtains data on climate, solar irradiation and atmospheric chemistry from field campaigns and in situ observatories worldwide ${ }^{24}$.

Another essential part of the global infrastructure for climate information coordination is the International Council for Science's World Data Service (https://www.icsu-wds.org). It is a fairly recent reorganisation (2008) of a world system of earth and environmental science data centres first instigated in the 1950s. Its mission is to promote 'universal and equitable access to, and long-term stewardship of, quality-assured scientific data and data services, products, and information.' It draws upon the long experience of these data centres (a notable one is PANGAEA, www.pangaea.de, which has pioneered initiatives for data publication and open access). Its multidisciplinary scientific committee is drawn from across the global change science community, and is geographically representative in its membership. The members are actively involved in data-rich research themselves, so they play a vital role in linking their respective communities to best practices and evolving policies for quality management, stewardship and compliance in research and policy.

\section{Quality infrastructure in model output}

One final feature of quality infrastructure in climate change science to highlight here is the particular importance of model intercomparisons. Climate (physical) and Earth system (coupled biogeochemical and physical) models are enormous and complex. They have evolved progressively within different research contexts. As a result, they incorporate different (but generally equally valid, in scientific terms) quantitative representations of Earth system processes. There is no single optimum way to approximate such complex processes, so the internal variability of models is an important feature of the science that needs to be understood in its own right. Model intercomparisons are internationally agreed, systematic, formally structured approaches to analyse within-model and between-model variability. Important initiatives include:

- The Coupled Model Intercomparison Project (CMIP, http://cmip-pcmdi.llnl.gov) is a forum for coordinating climate change model experiments that allow for systematic assessment and international cooperation. It defines a standard set of model simulations to tackle particular research needs (for instance, quantifying climate-carbon cycle feedbacks, or developing improved simulation realism for a particular timeframe). The collected model output is available for use by researchers, for use in climate impacts studies and scenario development work. The CMIP5 round informed the IPCC's Fifth Assessment Report.

- The Palaeoclimate Model Intercomparison Project (PMIP, http://pmip.lsce.ipsl.fr, and its spin-off for the carbon cycle, PCMIP, www.bridge.bris.ac.uk/projects/pcmip) use palaeodata (geological history) reconstructions as independent data for evaluating climate models.

- The Earth System Documentation project (http://es-doc.org) is a large global cooperative partnership that delivers metadata services for international model intercomparison projects.

- The Working Group on Coupled Modelling (WGCM, www.wcrp-climate.org/index.php/unifyingthemes/unifying-themes-modelling/modelling- $w g \mathrm{~cm}$ ) is the international research forum for the development and review of coupled climate models.

- The Integrated Assessment Modelling Consortium (IAMC, www.globalchange.umd.edu/iamc) is similar to the WGCM and CMIP, but focuses on the development of integrated assessment models that link climate models with models of technical and socioeconomic change. These models are an important source of information for climate policy responses, and are the workhorse models

\footnotetext{
${ }^{24}$ Issues relating to the actual global distribution of data stations will be discussed in later sections.
} 
for the IPCC's Working Group III on Mitigation of Climate Change ${ }^{25}$. These models are typically scientifically simpler in terms of process representation, but are conceptually and ontologically more complex than climate models (for instance, social processes are not 'predictable' in the same sense as physical processes). IAMC is promoting and developing protocols for model diagnosis, intercomparison, and coordinated studies.

\section{Knowledge for action}

The periodic global assessment reports of the IPCC are the iconic documentations of the state of knowledge of climate change. The IPCC is a scientific body developed expressly to assess the state of information worldwide that is relevant to the understanding of climate change. Its assessment reports review the science of the climate system, its biophysical and social impacts, and the available instruments and technologies available to mitigate climate change. It provides the baseline data and information for the UN Framework Convention on Climate Change (UNFCCC), and thus informs the decisions of the Conference of the Parties to the Convention. The COP is at the head of a complicated multi-body structure with responsibility for decision-making, implementation and compliance under the terms of the UNFCCC and its Protocols ${ }^{26}$.

\section{Key issues ${ }^{27}$ facing the climate change community}

Altogether, the climate change 'pipeline' from science through to real-world implementation represents some of the most elaborate institutional infrastructure established to date for measurement, standardization, certification, monitoring, verification and information stewardship (see table 4).

At the same time, there are known shortcomings in these systems that present major opportunities for governance coordination and technical cooperation internationally. These issues include:

- In many academic climate research contexts, quality management is not given as high emphasis as it is in commercial and public organisations, nor as in other fields of environmental science (e.g., atmospheric science, chemical pollution). This presents risks to the research community 28 that could be addressed by more widespread attention to the human aspects of the quality infrastructure. The interdisciplinarity of climate science paradoxically creates persistent silos of expertise (e.g., modellers vs observationalists, palaeo vs contemporary process scientists ${ }^{29}$, and quality issues can arise as information is exchanged at the interfaces. Global synthesis processes are therefore important in 'translating' science for other scientists, not just for policy people, and need to embed principles of transparency, accountability, and deliberative and inclusive participation for their intellectual legitimacy, not just their social and political legitimacy. Transparent procedures for continuing professional development might be beneficial.

- The quality of emissions inventories and national reporting: the basic requirements for a data inventory are that it should be transparent, comparable, consistent, complete and accurate. At present, the first two of these hold for emissions reporting; the different requirements for developed and developing countries mean that uncertainties in emissions inventories remain high (well over $10 \%$, even for developed countries where reporting systems are already rigorous). In principle, the UNFCCC includes both a policy-oriented quality validation stage (are guidelines for emissions inventories applied?), and a science-oriented quality verification process (are emissions reports 'true', and are real-world emissions actually changing as a result of policy?), but the latter is very constrained by the present quality infrastructure. In the next phase of

\footnotetext{
${ }^{25}$ IPCC Fifth Assessment Report, Climate Change 2014, Contribution from WGIII: http://mitigation2014.org. See chapters 2 and 6.

${ }^{26}$ https://unfccc.int/bodies/items/6241.php describes these various bodies and their roles.

${ }^{27}$ Disclaimer: this is not intended as a comprehensive or even a representative listing. It is based on the documents reviewed for this report, and on-going community discussions.

${ }^{28}$ The Climategate incident of hacked emails making public some frank exchanges between climate scientists is one example, discussed in Garud et al. (2014), Boundaries, breaches, and bridges: The case of Climategate, Research Policy 43(1), 60-73.

${ }^{29}$ For example, IPCC AR5 WGII, chapter 21 states: 'The growth of multi-model, multi-method, and multi-generational data for climate projections creates confusion for the IAV community'.
} 
climate negotiations, progress should be made towards regular (ideally annual) reporting by all countries, with independent checks of reporting and the level of uncertainty, addressing issues of consistency, completeness and accuracy ${ }^{30}$.

- Benchmarking of models against independent observational data - calls are increasing for climate models to be used in predictive mode, even at seasonal-to-decadal scales. This requires a much more comprehensive understanding of the regional nature of climate change and its impacts ${ }^{31}$, implying a need for much deeper worldwide collaboration. It also requires a major improvement in methodology and the available observational evidence base (palaeo, field/experiment and remote sensing data) for data-model comparison that is capable of addressing the complex dynamic processes involved in model predictions ${ }^{32}$.

- The problem of a drifting baseline in climate policy and targets is a serious concern in climate change (as in the other planetary boundary issues discussed in this report). On-the-ground measures are patchy in coverage, heterogeneous in quality, often ineffective, and too often opaque to stakeholders who have a right to transparency. In climate mitigation processes involving biosphere management, such as REDD+ (www.un-redd.org), approaches for the assessment of the actual effectiveness are weak ${ }^{33}$. Remote sensing approaches to MRV (Measuring, Reporting and Verification) are rapidly being developed, but methodological uncertainties are still high (methods currently may even still give the wrong sign - i.e., estimating losses instead of gains in stored carbon ${ }^{34}$ ).

- Developing a learning approach in quality management for climate change: 'learning' in a policy process involves structures for monitoring, recording, evaluating, and learning from experience, and identifying and implementing "best practices" and their characteristics ${ }^{35}$. This is difficult at the global level, especially where policy involves such complex multilateral environmental agreements as the UNFCCC. Nevertheless, lessons from other such agreements (notably the CBD) can be applied to the climate context. One particular such lesson is the role of the public: the CBD is more explicit about participation and precaution than the UNFCCC. Recently, there has been increasing stakeholder engagement and transparency (e.g., the voluntary REDD+ database), and processes and forums exist for collective learning and sharing of best practices.

\footnotetext{
$30 \mathrm{http}: / /$ mitigationpartnership.net/measuring-reporting-and-verification-mrv-0

31 Research needs are discussed in IPCC AR5 Working Group II Impacts, Adaptation and Vulnerability, chapter 21.

32 See the activities of the International Land Model Benchmarking Project (www.ilamb.org), which addresses model performance analysis and benchmarking of dynamic global vegetation models and coupled climate-carbon cycle models.

33 The REDD+ Partnership (http://reddpluspartnership.org) consists of countries supporting REDD+ action for climate mitigation,. It has commissioned reports on the effectiveness of REDD + , highlighting a need for coordination, improved monitoring, reporting and verification systems for carbon and non-carbon measures, and the need for improved social and ecological safeguards.

${ }^{34}$ Global Forests Observation Initiative Methods and Guidance Report 2014,

http://gfoi.org/sites/default/files/MGD_copyedited09042014.pdf.

35 There is a small body of literature addressing learning in climate policy, including Hilden, M. (2011), The evolution of climate policies: the role of learning and evaluations. Journal of Cleaner Production, 19, 1798-1811 (with a European focus); and Rao et al. (2006) Importance of technological change and spillovers in long-term climate policy. Energy Journal, p123-139 (with a focus on the global climate-energy system). The importance of learning in situations of high uncertainty is discussed in the seminal article by Sitkin et al. (1994) Distinguishing control from learning in total quality management: a contingency perspective, Academy of Management Review 19(3), 537-564.
} 
Table 4 - Summary of the state of the climate change quality infrastructure

\begin{tabular}{|c|c|c|}
\hline $\begin{array}{c}\text { Quality } \\
\text { infrastructure } \\
\text { element }\end{array}$ & $\begin{array}{c}\text { Context } \\
\text { (see page } 4 \text { for } \\
\text { explanation) }\end{array}$ & Issues \\
\hline Metrology & $\begin{array}{l}(\because \text { understanding } \\
\odot \text { assessing } \\
\odot \text { responding } \\
\odot \text { stewardship }\end{array}$ & $\begin{array}{l}\text { Basic science and scientific synthesis systems are robust (e.g., SI and IUPAC } \\
\text { standards; peer-review systems). Specialist measures are developed by } \\
\text { community consensus (e.g., definition of plant functional types and traits, } \\
\text { new remote sensing products). Assessment processes (e.g., IPCC) are } \\
\text { globally inclusive and transparent. } \\
\text { Major gaps exist in global data coverage for science, policy implementation, } \\
\text { and monitoring and verification. Gaps coincide with regions where } \\
\text { biophysical impacts of climate change are projected to be most severe. } \\
\text { Gaps correlate with places where national technical and institutional } \\
\text { capacity are low. Systems are not being re-evaluated to enable more } \\
\text { precautionary and adaptive responses in light of the progress of climate } \\
\text { change. }\end{array}$ \\
\hline Standardization & $\begin{array}{l}\odot \text { understanding } \\
\odot \text { assessing } \\
\odot \text { responding } \\
\odot \text { stewardship }\end{array}$ & $\begin{array}{l}\text { Basic climate research uses model intercomparisons for various purposes; } \\
\text { laboratory intercomparisons are less common (although key networks, } \\
\text { such as Fluxnet, have good quality systems), and systematic data-model } \\
\text { comparison is relatively uncommon. IPCC reports (especially WGII, on } \\
\text { climate impacts) continue to flag the difficulty of compiling and comparing } \\
\text { data. } \\
\text { The climate policy process gives high priority to worldwide technical } \\
\text { standards, and institutions and instruments are in place for capacity } \\
\text { development, technical cooperation. }\end{array}$ \\
\hline $\begin{array}{l}\text { Conformity } \\
\text { assessment }\end{array}$ & $\begin{array}{l}\odot \text { understanding } \\
\odot \text { assessing } \\
\bigodot \text { responding } \\
\odot \text { stewardship }\end{array}$ & $\begin{array}{l}\text { Globally, there is fairly low uptake in climate science of formal systems for } \\
\text { certification, accreditation and auditing of scientists and research labs, } \\
\text { compared with other science and technology fields. Participation in state- } \\
\text { of-the-art assessments provides impetus for worldwide coordination and } \\
\text { harmonisation. The open and transparent processes of expert nomination } \\
\text { by governments serve as a form of accreditation. } \\
\text { Despite international agreement on climate policy, and the availability of } \\
\text { detailed technical information, institutions and instruments for climate } \\
\text { mitigation and adaptation action, systems assuring conformity and } \\
\text { compliance are weak. A growing focus on stakeholder engagement and } \\
\text { transparency serves as an auditing mechanism for some processes. }\end{array}$ \\
\hline $\begin{array}{l}\text { Quality } \\
\text { management }\end{array}$ & $\begin{array}{l}\odot \text { understanding } \\
\odot \text { assessing } \\
\odot \text { responding } \\
\odot \text { stewardship }\end{array}$ & $\begin{array}{l}\text { In many academic climate research contexts, professional } \\
\text { accreditation/registration and quality management is not given the same } \\
\text { emphasis as it is in commercial and public organisations, nor as in other } \\
\text { fields of environmental science (e.g., atmospheric science, chemical } \\
\text { pollution). Public interest has ensured that the processes of information } \\
\text { gathering have evolved notably over time (e.g., improvements in process, } \\
\text { inclusiveness, and output communication in the IPCC assessments). } \\
\text { Climate policy is not reducing the climate change problem. This can be } \\
\text { framed as a failing in quality assessment and assurance at the global level. } \\
\text { A precautionary approach that accepts biophysical 'absolutes' would seek } \\
\text { to strengthen the quality infrastructure for climate to halt } \mathrm{CO}_{2} \text { emissions in } \\
\text { the near term, rather than simply reprofiling missed targets to later in the } \\
\text { future. }\end{array}$ \\
\hline
\end{tabular}


In the last couple of decades, attention has focused on the accurate measurement of $\mathrm{pH}$ and the carbon dioxide system in seawater. The chemical changes associated with increased anthropogenic $\mathrm{CO}_{2}$ in the oceans are termed ocean acidification - a simple term for a very complex set of physical and chemical processes, with important biological consequences. At present, characterising the carbonate chemistry of a seawater sample is not straightforward.

Different disciplines (such as marine ecology, physiological chemistry, and ocean geochemistry) have addressed ocean acidification from different perspectives, developing distinct analytical traditions. A large number of terms and units are in current use, addressing different processes within the carbon dioxide system. Concentrations are expressed either by volume or by mass; and there are more than one definitions of "total" inorganic carbon. There are also currently multiple analytical methods in use for ocean acidification, based on different but related titration procedures.

Even $\mathrm{pH}$ - perhaps the most fundamental parameter in this rapidly evolving field - is problematic. In the environmental sciences, standard procedures involve the use of calibration buffers prepared in synthetic seawater (itself a standardized product, with high concentrations of salt and sulfate ions compared with pure water). Physiological studies use a $\mathrm{pH}$ scale based on the free hydrogen ion concentration, which does not include the chemical effect of other dissolved ions. Methods are now being developed that allow for the conversion between the total ion scale and the free ion scale.

The European Project on Ocean Acidification (EPOCA) was the first large-scale international initiative to coordinate knowledge about the changes in ocean chemistry and biogeography. It has provided important international leadership in harmonising data issues across communities, and creating a data system according to international standards and protocols (ISO, SOAP, WSDL, XML, netCDF).

Key information sources: Dickson, A.G. (2010) Seawater carbonate chemistry. In: Guide to best practices for ocean acidification research and data reporting, U. Riebesell et al., eds., Publications Office of the European Union; and the EPOCA project, www.epoca-project.eu.

\section{Ecosystem change and biodiversity loss}

Ecosystem change is often regarded as a local-scale issue, and impacts of biodiversity loss are usually first felt locally. International biodiversity policy has therefore tended to enshrine subsidiarity 36 (finding the right level for governance interventions), in the broad sense. However, the planetary role of functioning ecosystems increasingly needs to be kept in mind ${ }^{37}$.

From a global perspective, the integrity of the world's biomes, or large-scale ecosystems, is an important control on Earth system functioning and stability. For example, forests - especially in the tropical and boreal regions - and ice-covered/polar ecosystems have fundamental links to the physical climate system and the global carbon cycle, and to regional and global hydrological patterns (with strong positive feedbacks to climate). The role of desertification of drylands in Earth system functioning is somewhat less well understood than these other biomes, but it is also known to involve large scale systemic feedbacks between land cover, the water cycle, and atmospheric dust and aerosol. The risks of ecosystem change to the ecosystem services on which humanity depends have been assessed in the TEEB report ${ }^{38}$, and in some regional assessments (e.g., UK's 2011 National Ecosystem Assessment).

Rockström and colleagues proposed that the global rate of species loss could serve as a general indicator of the impact of human activities on biologically mediated Earth system processes. In defining their proposed boundary, they argued for at least a ten-fold reduction in the current

\footnotetext{
${ }^{36}$ As discussed in Espinosa, M.F. and Louafi, S. (2005) Governance of biodiversity. In: Biodiversity, Science and Governance, R. Barbault, et al., eds., UNESCO, Muséum national d'Histoire naturelle, and Institute français de la biodiversité.

${ }_{37}$ Cardinale, B. (2012), Impacts of biodiversity loss. Science 336, 552-553; and Reich, P.B. et al. (2012), Impacts of biodiversity loss escalate through time as redundancy fades. Science 336, 589-592.

38 www.teebweb.org
} 
extinction rate, to 10 extinctions per million species-years. This proposed boundary represents a radical transformation in humanity's use and conservation of the biosphere - the 2005 Millennium Ecosystem Assessment projected that extinctions could increase by a factor of 10 or more in the coming century ${ }^{39}$. Such predictions are based on our knowledge of past mass-extinction events, which indicate that biodiversity loss is not a gradual linear process, but rather an abrupt or exponential one.

Ecologists and biodiversity scientists are currently debating whether alternative measures of human impact on global ecological functioning would be more useful and implementable than species extinction rate. The mean species abundance ${ }^{40}$ in a given area is a measure used in many policy contexts (e.g., the UNEP GEO reports, OECD environment reports, and the CBD's Biodiversity Outlooks). One advantage of this measure is it can be incorporated into global ecosystem models, to help investigate the possible impacts of climate change and other human pressures.

\section{The current state ${ }^{41}$}

Current estimates are that the rate of species extinction is 100-1000 times the baseline rates seen over Earth's history. However, there are major difficulties in implementing a quality infrastructure for the determination of baseline rates. This is an especially significant concern because the processes involved are non-linear.

Habitat loss and ecosystem degradation are measured and monitored reasonably well, both on the ground and from Earth observation. Both are widespread. Deforestation rates are estimated to be approximately $1 \%$ of original forest per year. About $80 \%$ of the world's commercial fisheries are fully exploited, and processes like ocean acidification add indirect threats to the direct human impact associated with the over-extraction of natural resources (e.g., fishmeal and fisheries), and the physical disturbance of productive regions (reefs, coasts).

At the same time, while important progress has been made in establishing protected areas, many countries are lagging far behind their committed targets for conservation under the CBD. Figure 6 shows the regional distribution of the world's protected areas (note the dominance of sites in Europe). Marine conservation has generally lagged behind the protection and restoration of land habitats. $13 \%$ of the world's land area is protected, against an internationally agreed target of $17 \%$ by 2020 . Just $1.6 \%$ of coastal and marine area is protected, against the target of $10 \%$.

\footnotetext{
${ }^{39}$ Mace, G. et al (2005), Biodiversity. Chapter 4 in Ecosystems and human wellbeing: current state and trends, Island Press, p79-115. 40 The method is described in Alkemade, R. et al. (2006). GLOBIO 3: Framework for the assessment of global terrestrial biodiversity. In A.F. Bouwman, et al., eds., Integrated Modelling of Global Environmental Change. Netherlands Environmental Assessment Agency, Bilthoven.

41 The Millennium Development Goals Report 2012 and MDG 72013 status update reports that: 'Biodiversity is still being lost, even as more areas of the earth's surface are protected'; 'Since 1990, protected areas have increased in number by 58 per cent. Growth in protected areas varies across countries and territories, and not all protected areas cover key biodiversity sites. By 2010 , protected areas covered 12.7 per cent of the world's land area but only 1.6 per cent of total ocean area.' (www.un.org/millenniumgoals/environ.shtml).

The UNEP-WCMC Protected Planet Report 2012 reviews progress on conservation and protected area targets: www.unepwcmc.org/medialibrary/2012/09/14/eb3bb854/PPR2012_en.pdf.

The Convention on Biological Diversity reports in detail on trends within its biodiversity remit: CBD (2010) Global Biodiversity Outlook 3. www.cbd.int/gbo3/?pub=6667\&section=6673.

The most comprehensive global assessment of ecosystem change is still the Millennium Ecosystem Assessment (2005) Biodiversity and human wellbeing: current states and trends, Island Press, available on www.maweb.org, plus new reports from the IPBES SubGlobal Assessments repository: http://ipbes.unepwcmc-004.vm.brightbox.net and PECS IPO, Stockholm.
} 


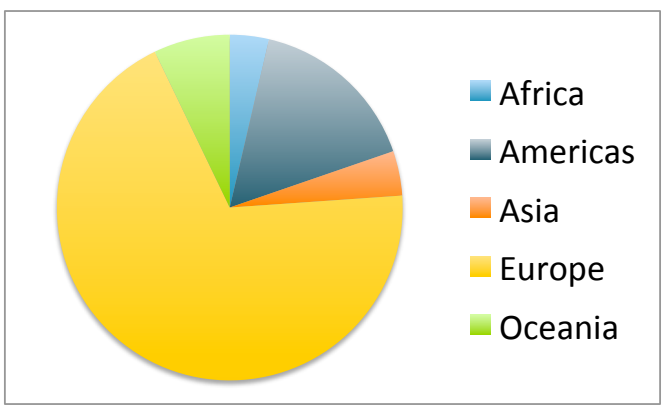

Figure 6 - The regional distribution of the world's protected areas (compiled from data from the IUCN/UNEP World Database of Protected Areas, which documents over 210,000 sites; www.protectedplanet.net)

The figure below (from an analysis by Brooks and colleagues) ${ }^{42}$ shows the world's 'crisis ecoregions' and biodiversity hotspots, where land ecosystems are under high threat of human perturbation (panel A), and 'last of the wild' areas where proactive conservation approaches would be necessary to protect remaining natural habitat (panel B). It is clear that very large areas of the world are consistently emphasized as priorities for conservation (the intensely shaded areas show strong agreement among multiple approaches).
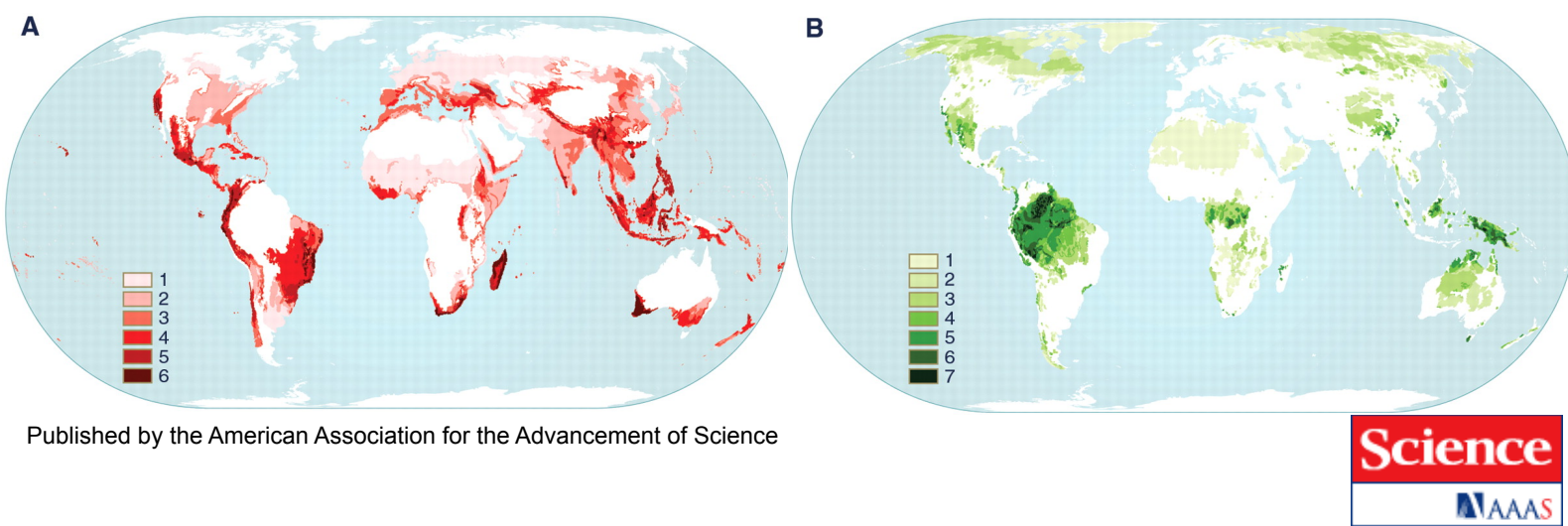

Figure 7 - Conservation priorities for the world's terrestrial ecosystems: 'crisis ecoregions' (A) and 'last of the wild' areas (B). Intensely coloured regions show where there is strongest agreement between multiple conservation priority approaches in recent use. (Image reproduced from Brooks, T.M. et al. (2006), Global biodiversity conservation priorities. Science, 313 (5783), 58-61).

The most biodiverse places are often both the most threatened and the poorest economically. Brooks and colleagues argue that this places particular responsibilities on decision-makers in charge of globally flexible conservation funding (i.e., multilateral agencies, bilateral aid, and private funders). The map also shows regions at risk of biodiversity loss in many parts of the developed world. In these locations, the pressing issue is not a lack of data or information, or even of policy; it is rather a failure in implementation. For ecosystem change (as for most processes), an even spatial spread of information is crucial to information quality infrastructure. The Brooks analysis can thus also be interpreted as a map of need for a global quality infrastructure for biodiversity conservation and sustainable ecosystem management.

Many of the largest protected areas are currently essentially inaccessible (e.g., the densest areas of Amazonian and West African forest, the Greenland ice sheet). It is statistically difficult to determine whether it is the system of conservation policy, legislation and regulation that actually protects them, rather than their current remoteness. In contrast, small-sized protected areas generally have sharp boundaries between the ecosystem of interest and the human-dominated system around it. Human demands for land are constant pressures even on protected areas. The phenomenon of protected area downgrading, downsizing, and degazettement is a concern in many parts of the world ${ }^{43}$.

\footnotetext{
42 Brooks, T.M. et al. (2006), Global biodiversity conservation priorities. Science, 313 (5783), 58-61

${ }^{43}$ Tracked on www.padddtracker.org, an online interactive map produced by WWF. See also Joppa et al. (2008), On the protection of 'protected areas', PNAS 105 (18) 6673-6678, www.pnas.org/content/105/18/6673.full.
} 


\section{Links to freshwater use, land use, and the atmospheric aerosol burden}

The main drivers of biodiversity loss 44 are directly related to human use of land and freshwater resources: deforestation, desertification, over-exploitation, invasive species, and the pollution of air, water and soils. The biosphere also plays a vital part in regulating the climate system.

Evapotranspiration by vegetation is a major component of the water cycle. Organic compounds given off by vegetation are important in cloud formation, and are part of the chemical cycles in the atmosphere that break down ozone and other gases that are harmful to living organisms. Deforestation and pollution affect these processes (Figure $8^{45}$ ).
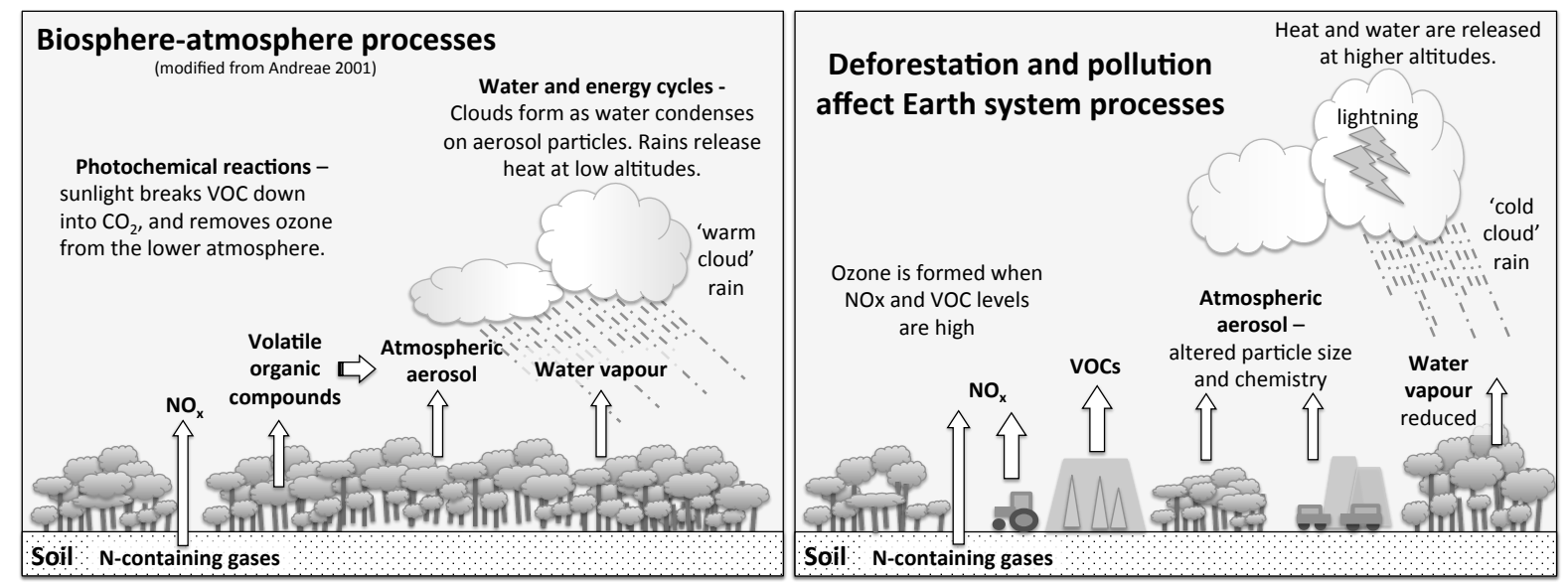

Figure 8 - Ecosystem change and biodiversity loss are closely related to land use, the freshwater cycle, and atmospheric chemical processes.

\section{The quality infrastructure for ecosystem change and biodiversity loss}

The global biodiversity and conservation community is organizing itself in similar ways to the climate change community, in order to better understand and respond to ecosystem change. Figure 9 gives an indication of the coverage of different kinds of ecological and biodiversity data and information.

\footnotetext{
${ }^{44}$ Reviewed in the Millennium Ecosystem Assessment, 2005 (www.maweb.org) and the regular CBD Global Biodiversity Outlook reports (www.cbd.int/gbo3).

45 This is discussed in depth in the Millennium Ecosystem Assessment, especially chapters 3, 7 and 13. The figures are based on the analysis of Andreae, M.O. (2001), The Biosphere: pilot or passenger on Spaceship Earth? In: Contributions to Global Change Research, Heinen, D. et al., eds., WBGU, p59-66.
} 


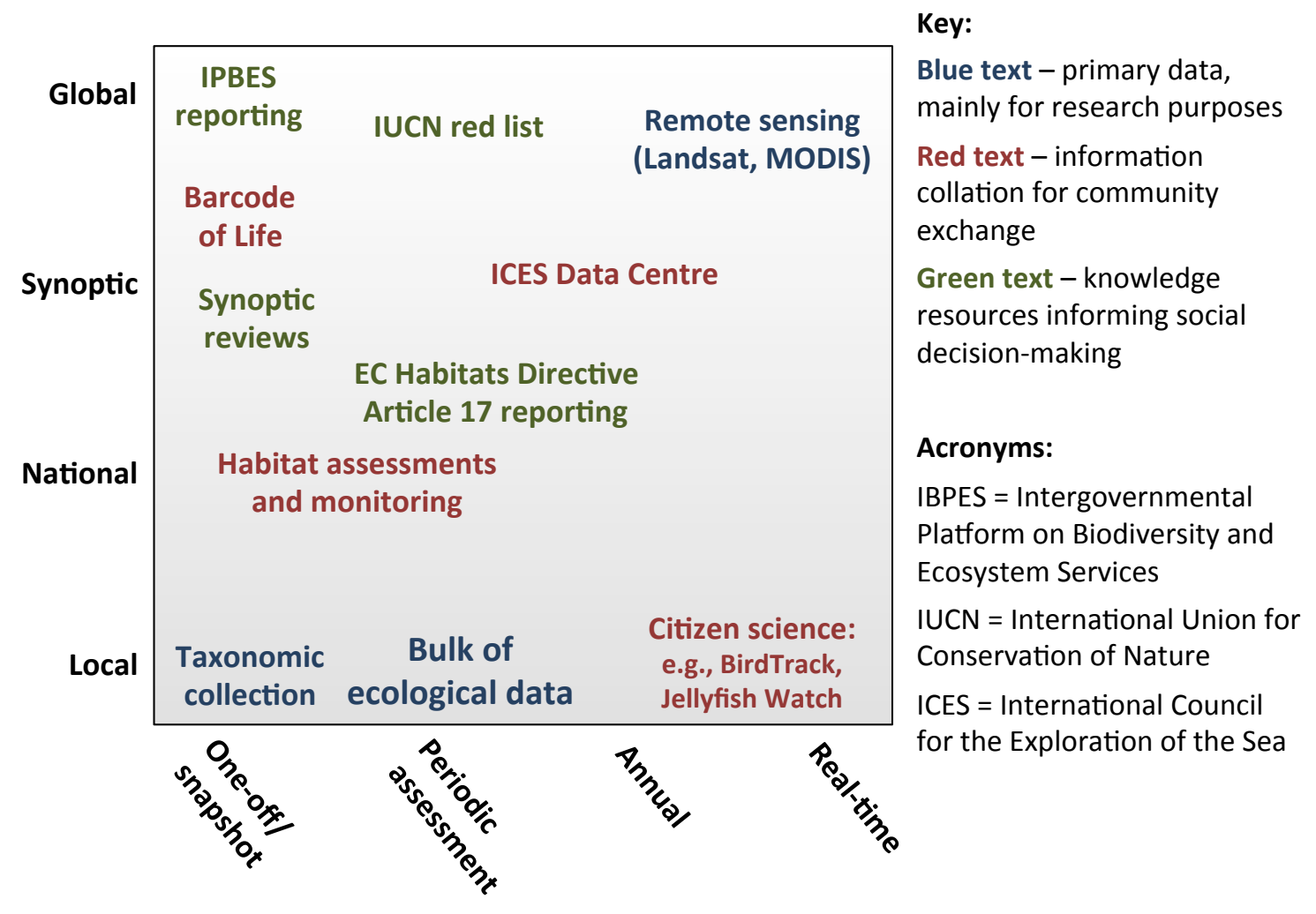

Figure 9-An indication of the spatial and temporal coverage of biodiversity and ecosystem information.

\section{From a mosaic of data to global information}

Ecological data relates to the relationships between organisms, populations, communities and ecosystems with their physical environment. The methods of ecology have a very long tradition natural history is one of the first fields of study to be documented - so scientific norms, practices and units of analysis are very well established. Biodiversity observations are among the longest and most numerous recorded data on the environment.

However, global change is driving a new focus on global ecology, requiring new attention to many issues of metrology. At the more complex levels (ecosystems, landscapes, the planet), experimental research in ecology is difficult to carry out. Tools for data gathering include field surveys (including remote sensing), mapping projects, and monitoring. Data are typically multivariate, complex, and 'noisy'. Most studies are descriptive, and the results are necessarily more context-specific than is the case for the physical sciences, yet demand is growing for predictive power ${ }^{46}$. As the climate change experience has demonstrated, with such power comes new responsibilities and quality infrastructure requirements for science, both as a process and a profession.

Important global processes for coordination and synthesis of data into information include the establishment of research networks providing global coverage and extended time-series observations, such as:

- The International Long-Term Ecological Research Network (ILTER, www.ilternet.edu/member-networks), a 'network of networks' such as the European ALTER-Net (www.alter-net.info). As in other global environmental information activities,

\footnotetext{
${ }^{46}$ For example, the strategic scope recommendations from UNEP to IPBES:

www.ipbes.net/images/UNEP\%20submission\%20to\%20IPBES\%20on\%20biodiversity $\% 20$ and $\% 20$ ES\%20modelling.pdf. A good discussion of the issues, including data management, is in Hampton, S.E. et al. (2012), Ecological data in the Information Age. Frontiers in Ecology and the Environment 10: 59-59, www.esajournals.org/doi/abs/10.1890/1540-9295-10.2.59?journalCode=fron
} 
Europe and the US have good coverage; southeast Asia, south Africa and Latin America have some coverage, while major parts of the world remain unrepresented.

- The data portals of the International Council for the Exploration of the Sea (e.g., http://ecosystemdata.ices.dk), an intergovernmental organisation at the science-policy interface for marine environment issues, with a particular remit for the international marine conventions in the European region (HELCOM, OSPAR).

- The North Pacific Marine Science Federation (PICES, https://www.pices.int/projects/default.aspx) is a similar intergovernmental scientific organisation, established to promote and coordinate marine research in the northern North Pacific and adjacent seas. Various of its working groups and projects deal with data quality, metadata standards and protocols, and model development and intercomparison.

In the same way as for climate change science, a large proportion of ecological data are typically obtained through ad hoc, site-based scientific campaigns, giving patchy coverage (in both taxonomic and geographic terms) and short time series. Problems of poor continuity, consistency and documentation hamper reuse and application in other contexts, especially under conditions of rapid environmental change. Where systematic monitoring programs exist, they focus on selected elements of biodiversity (e.g., birds). When there is a clear policy driver, these aspects of data quality are much improved, but policy-driven data are not always optimal for research purposes.

To address the problems relating to sparse monitoring sites, there is a growing emphasis on less direct measures derived from satellite-borne remote sensing and other forms of remote mapping. The Group on Earth Observations Biodiversity Observation Network (GEO BON,

https://www.earthobservations.org/geobon.shtml) is an important worldwide network, recognized by the Parties to the CBD that engages government organisations, conservation bodies, and other expert groups. It seeks to improve biodiversity observations globally, and make data, information and forecasts more readily accessible to users in research, policy and practice. It promotes full and open exchange of data, applying the Global Earth Observation System of Systems Common Infrastructure, to implement consistent standards to enable interoperability.

GEOBON recently assessed the adequacy of the world's observing systems for biodiversity ${ }^{47}$, at the request of the CBD. Their conclusion was that these systems are broadly adequate to track progress against the CBD targets on the state of biodiversity, and the effectiveness of conservation action. Observing systems are much weaker when in comes to tracking the human drivers of biodiversity loss, the benefits derived from biodiversity, and the actual mechanisms of the CBD itself. None of these issues are technically infeasible. The report points out that improving knowledge of biodiversity is an important issue to address, as part of improving knowledge transfer.

\section{The knowledge basis for society's responses}

The knowledge community engaged with biodiversity and ecosystem change differs in an important way from that engaged with climate: in addition to the academic community, many intergovernmental and non-governmental organisations and conservation societies play a prominent role in co-producing, managing, and sharing collective knowledge about ecosystems.

- The Global Biodiversity Information Facility (GBIF, www.gbif.org) facilitates the digitization of biodiversity data for global dissemination, helping redress the problem that the vast majority of data and collections are in the developed world (see also www.gbif.org/infrastructure/summary). It is an intergovernmental initiative, with countries, economies and international organisations as members.

- UNEP and the IUCN have cooperated to develop the World Database on Protected Areas (www.wdpa.org), with input from governments and NGOs. It is a powerful public engagement and public awareness tool - people around the world can access the global map

\footnotetext{
47 https://www.earthobservations.org/documents/cop/bi_geobon/2011_cbd_adequacy_report.pdf
} 
of protected areas (www.protectedplanet.net) to see what the situation is in their locality. HIgh levels of citizen engagement are recognised as important elements in the quality infrastructure for responses to ecosystem change (e.g., CBD Aichi Targets 1, 17 and 18, www.cbd.int).

- The Global Forest Resources Assessment (www.fao.org/forestry/fra) combines national reporting to the UN FAO with remote sensing evidence. The assessment that is currently underway (FRA 2015) has a changed scope from previous reports, with important quality infrastructure implications. It has a greater emphasis on international capacity building, user needs, and more strategic communications for cooperative learning.

- The Biodiversity Indicators Partnership (www.bipindicators.net) plays a key role in defining new measures for use in understanding, assessing and monitoring biodiversity and ecosystem change. It is also a multi-stakeholder forum bridging science to policy and practice.

- The Living Planet Index (www.panda.org/lpr) is an initiative for communication about the trends in populations of animal species. It was developed by WWF and the research branch of the Zoological Society of London, with UNEP-WCMC data; it is now part of the BIP system. It is a global indicator, but work has been done on developing national and regional versions, for Uganda, Canada, Mediterranean wetlands and Arctic species. Indices like the LPI can provide an impetus for countries to improve the standardization, quality assurance and conformity of their data.

The biggest area of debate in ecosystem change and conservation arenas is how to deal with the links between biodiversity and human well-being. These links are core to the CBD Targets 1, 2, 14, 18 and 19. They require new ways of dealing with social data, on which they rely, and of overcoming deep methodological differences between ecology and economics. They also have fundamental implications for the ethics and politics of sustainability - issues that are often not addressed in the same forums as those dealing with mainstream quality infrastructure.

The application of the ecosystem services idea is an area where policy has outstripped research and the evidence base. The GEOBON report (footnote 48) points out that 'attitudes to and awareness of ecosystem services and the relationship to biodiversity and human well-being are hardly known at all at the global level, using consistent approaches. There is thus no global baseline to measure against.' Only the European Union has so far set up a regional baseline. The Ecosystem Services Partnership (www.es-partnership.org /esp/79128/5/0/50) is a researcher-led initiative set up in response to the sparseness and heterogeneity, in both methods and quality, of ecosystem services valuation (in monetary terms). It builds upon the TEEB Report's Ecosystem Services Valuation Database and provides links to other databases and information resources on ecosystem services.

The World Resources Institute is piloting a new database and forum for indicator development for ecosystem services, the benefits (both monetised and not) to society that ecosystems provide. This is a valuable, well-structured (and still too rare) compilation of information. However, its website (www.esindicators.org/\#about) confirms that 'only a portion of compiled indicators are focused specifically on ecosystem services'. Anecdotal examples may actually be the best form of information to inform social learning and decision-making, but it is problematic to treat them and present them as a comprehensive and consistent data resource. It could be argued that the process is more important than the product in this case, and more effort could usefully be placed on broader-angled quality management, co-development and learning aspects than strictly on quality control. 


\section{Key issues ${ }^{48}$ facing the biodiversity and ecology community}

A major effort is underway to improve the 'pipeline' from ecosystem science through to real-world action to protect biodiversity and prevent ecosystem degradation in ways that threaten human wellbeing. Since 1992, and the Convention on Biological Diversity, major efforts have been made to create an institutional infrastructure for measurement, standardization, certification, monitoring, verification and information stewardship. In contrast with climate change, this process began from a more fragmented and diverse knowledge community, and embedded subsidiarity as a principle in its response to the problem. This means that ecological protection is institutionally 'relative' rather than absolute.

A major problem that therefore arises is that the world has become very effective at tracking our own ecological decline, but not halting it. Effort is currently being made to improve the exchange of knowledge and the co-development of more effective responses to ecosystem harm and biodiversity loss. The Intergovernmental Platform on Biodiversity and Ecosystem Services (IPBES, www.ipbes.net) has been set up with the aim of strengthening dialogue not just between the scientific community and governments (as in the IPCC), but also with other stakeholders worldwide.

Several characteristics of the biodiversity and ecosystem change systems present major challenges for a quality infrastructure, governance coordination and technical cooperation internationally:

- Biodiversity is unavoidably local. While ecosystem change has now become a global problem, there is no substitute for knowledge of dynamic biological processes, physical realities, and societal concerns at the very local level. Current systems for global responses are not well equipped for bridging these scales, and some measures for legal metrology and standardization devised for a specific context is likely to be very inappropriate for others. Many citizen science initiatives have proved to be valuable in addressing this challenge for data gathering, monitoring, 'truth-checking', and social learning (Box 4).

- Biodiversity loss is irreversible on human timeframes. The current rates of human-caused depletion of biological diversity at all levels (genetic, species, ecosystems) is internationally recognised as a global risk, and the persistent failure of precautionary measures to stem the loss is a very serious issue ${ }^{49}$. The CBD failed to meet its 2010 targets, largely rolling them over to 2020. The quality infrastructure must address the shifting baseline.

- Ecological systems are complex, not controllable. A great deal is unknown about the biophysical functioning of ecosystems, and much of this is the irreducible uncertainty that is characteristic of all living systems. Non-standardizable features like redundancy and adaptability are essential to ecosystem resilience. The maxim 'What gets measured gets done' was not designed for complex systems where high variability and surprise are a natural feature. Adaptive features need to be inbuilt in the quality infrastructure. The global policy domain for biodiversity and natural resources management has partly grasped this issue, for instance, by beginning to institutionalize stakeholder engagement as a way of improving the technical quality of knowledge and ensuring that action is more responsive and appropriate. There is still a great need for thought and debate about how a quality infrastructure can be meaningfully embedded throughout this complex system.

\footnotetext{
${ }^{48}$ Disclaimer: this is not intended as a comprehensive or even a representative listing. It is based on the documents reviewed for this report, and on-going community discussions.

${ }^{49}$ For example, the World Bank's World Development Report 2014 (http://siteresources.worldbank.org/EXTNWDR2013); the World Economic Forum's Global Risks Report 2014 (http://www3.weforum.org/docs/WEF_GlobalRisks_Report_2014.pdf); Kanongdate et al. (2012) Has implementation of the precautionary principle failed to prevent biodiversity loss at the national level? Biodiversity and Conservation 21 (13), 3307-3322; Duarte C.M. et al. (2008) Return to Neverland: shifting baselines affect eutrophication restoration targets. Estuaries and Coasts DOI 10.1007/s12237-008-9111-2.
} 
Table 5 - Summary of the state of the biodiversity and ecosystem change quality infrastructure

\begin{tabular}{|c|c|c|}
\hline QI element & Context & Issues \\
\hline Metrology & $\begin{array}{l}\odot \text { understanding } \\
\odot \text { assessing } \\
\odot \text { responding } \\
\odot \text { stewardship }\end{array}$ & $\begin{array}{l}\text { Long-established, well-tested and widely accepted techniques have } \\
\text { been developed for understanding ecology at local scales. However, } \\
\text { these are poorly suited for application at the global level, both for } \\
\text { global change research and for society's responses to ecosystem } \\
\text { change. Global synthesis reports highlight geographic, taxonomic, } \\
\text { and theoretical gaps. Progress is being made on indicator } \\
\text { development and correspondence assessment between large-scale } \\
\text { observations and on-the-ground ecological reality. }\end{array}$ \\
\hline Standardization & $\begin{array}{l}\odot \text { understanding } \\
\odot \text { assessing } \\
\odot \text { responding } \\
\odot \text { stewardship }\end{array}$ & $\begin{array}{l}\text { The term 'biodiversity' embeds many concepts and meanings, and is } \\
\text { applied in different ways in different research and policy contexts. } \\
\text { This presents challenges for overall standardization. The definition of } \\
\text { the CBD sets the scope for global assessments and a major strand of } \\
\text { society's response to ecosystem change, and serves as a } \\
\text { standardization mechanism enabling coordination and cooperation } \\
\text { among partners. However, this scope is not adequate for the long- } \\
\text { term stewardship of the biosphere, as the missed } 2010 \text { targets show. }\end{array}$ \\
\hline $\begin{array}{l}\text { Conformity } \\
\text { assessment }\end{array}$ & $\begin{array}{l}\Theta \text { understanding } \\
\odot \text { assessing } \\
\odot \text { responding } \\
\odot \text { stewardship }\end{array}$ & $\begin{array}{l}\text { As for climate, uptake is low for formal certification, accreditation } \\
\text { and auditing of scientists and research labs, except for public labs } \\
\text { providing commercial services, where ISO certification is widespread. } \\
\text { Policy processes (mainly CBD) are improving flows of technical } \\
\text { information, and scrutiny systems for national reporting, etc. } \\
\text { Systems assuring conformity and compliance are weak. The CBD has } \\
\text { a strong focus on stakeholder engagement, and this higher } \\
\text { transparency serves as an auditing mechanism for some processes. }\end{array}$ \\
\hline $\begin{array}{l}\text { Quality } \\
\text { Management }\end{array}$ & 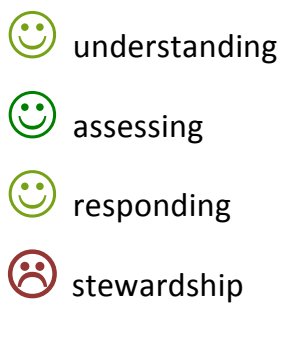 & $\begin{array}{l}\text { Quality management developed for local-level ecology research is } \\
\text { strained in the global context. The creation of the IPCC-like IPBES is } \\
\text { an effort to improve science-policy processes, inclusiveness, and } \\
\text { output communication. Global state-of-play assessments and policy } \\
\text { are supported by effective multi-stakeholder, multi-national } \\
\text { networks (e.g., CBD Secretariat, FAO, UNEP-WCMC). } \\
\text { Environmental protection policy is not reducing the problem, and } \\
\text { baselines are repeatedly shifted - a clear failing in quality } \\
\text { assessment and assurance at the global level. }\end{array}$ \\
\hline
\end{tabular}




\section{Box 3 - Essential Biodiversity Variables? An example of a potential new quality infrastructure}

'EBVs are those things that... ...in 50 years time, everybody will be thankful that we had the foresight to start recording now'. Prof Robert Scholes, GEOBON.

Discussions are underway about a set of 'essential biodiversity variables' (EBVs), analogous to the GCOS Essential Climate Variables used in modelling and assessments for the UN Framework Convention on Climate Change. The extensive biodiversity research community recognises the need to serve a broad community of users - the CBD and related policy processes, but also the wider global change research community and biodiversity custodians in wider society.

EBVs clearly need to be sensitive to change over time. To be globally applicable, they need to be focused on biodiversity 'state' variables (social drivers and physical covariates may be useful, but are not essential to include). To be generalizable and applicable to many forms of biodiversity, they are likely to be intermediate between primary observations and high-level indicators of biodiversity change. They may be of relevance to the broader biodiversity community and prove useable and useful for many purposes, but they need to be focused on a particular set of purposes in order to be manageable and implementable. They need to build on measurement systems that are already in place. Expert deliberation for the selection of these variables needs to be complemented by a high degree of community consensus if they are to become the basis of monitoring programmes worldwide. EBVs should be technically and economically feasible in terms of monitoring. These are the considerations that are currently being made.

Key information sources: GEOBON report on Adequacy of the Biodiversity Observation Systems (footnote 48); Pereira H.M. et al. (2013) Essential biodiversity variables. Science 339 277-278.

\section{Box 4 - Citizen science helps to bridge the local to global knowledge gap}

Citizen science is a growing trend. One motivation is simply that data quantity is often a major component of data quality, and citizen engagement enables large data sets to be gathered at low cost. The approach is well suited to gathering georeferenced presence/absence data. It is typically used to obtain baseline conditions (frequency and extent) of an issue (as in Jellyfish Watch), or a national snapshot of an issue (the annual RSBP Big Garden Birdwatch in the UK). It requires the development and pilot-testing of a common, standardized protocol, including systematic data recording. Data gathering involves citizens uploading data to the website database or through a mobile app. It has become an important feature in ecology studies. For instance, Jellyfish Watch has a Clean Seas option, where participants log occasions of normal conditions, with no jellyfish or red tides (nuisance plankton blooms).

These initiatives build an important information resource, for research and also for policy and civil society. Often, they link social and environmental dimensions in ways that are important for sustainability. Initiatives like the Millennium Earth project of the Institute for Conscious Global Change have helped to make visible issues relating to the 'on the ground' implementation of internationally agreed development goals, spotlighting areas of concern.

The best citizen science has mutual learning and widened engagement at its heart. The Tea Bag Index is an example of an initiative that engages the world's public in a rather arcane aspect of global change science - soil organic carbon decomposition rates, a key variable in many climate and carbon cycle models. It benefits from the standardization and quality control processes of tea manufacturers to ensure that its own protocols are robust (participants bury a tea bag $8 \mathrm{~cm}$ deep in soil, using the length of the tea-bag label as a check). With the tagline Can drinking tea help us understand climate change? it emphasises the power-by-numbers principle and the need for global coverage to inform process understanding. Researchers involved have engaged in novel ways with businesses, conventional and social media, and a very diverse sub-section of society - tea-drinkers around the world.

Examples and information sources:

- Ecosystem change and biodiversity citizen science initiatives: Jellyfish Watch, www.jellywatch.org (public website), and www.ciesm.org/marine/programs/jellywatch.htm (science website); www.rspb.org.uk/birdwatch

- Biogeochemical change: Tea Bag Index, www.decolab.org/tbi

- Social-environmental change: Institute for Conscious Global Change - www.consciousglobalchange.org; and work in progress on MyUNEPLive (www.unep.org)

- $\quad$ Science Communication Unit, University of the West of England, Bristol (2013), Science for Environment Policy In-depth Report: Environmental Citizen Science. European Commission DG Environment. http://ec.europa.eu/science-environment-policy

- $\quad$ Roy et al. (2012) Understanding citizen science and environmental monitoring. UK Environmental Observation Framework. www.ceh.ac.uk/products/publications/documents/citizensciencereview.pdf 


\section{Perturbed biogeochemistry: nutrient element releases to land and aquatic ecosystems}

Nitrogen and phosphorus are among the essential elements that comprise life; their global cycles underpin the functioning of the whole Earth system. The world now faces an enormous challenge in producing more food and energy without eroding its life-support systems ${ }^{50}$. The environmental release of nitrogen and phosphorus is becoming an unaffordable waste of natural resources. It leads to perturbation of land and marine ecosystems, with severe impacts on regional air and water quality. This alteration of global biogeochemical cycles therefore also has consequences for the climate system ${ }^{51}$.

Rockström and colleagues proposed 'as a first guess' that industrial and agricultural fixation of $\mathrm{N}_{2}$ gas into reactive forms of $\mathrm{N}$ should be limited to $35 \mathrm{Tg} \mathrm{N} \mathrm{yr}^{-1}, 25 \%$ of its current value. This boundary is framed in terms of a key human driver of biogeochemical perturbation (synthetic nitrogen fixation). The advantage is that this is an issue that can be controlled, in principle at least. The disadvantage is that it does not relate directly to the biophysical processes and impacts in important ways. First, the $\mathrm{N}$ boundary could be achieved and the problem remain, because where and how $\mathrm{N}$ is released is as important as how much. Similarly, it is likely that current levels of synthetic N fixation can be assimilated beneficially by ecosystems, depending on where and how the $\mathrm{N}$ is applied (large parts of the world are $\mathrm{N}$-depleted).

More recent analysis by de Vries and colleagues ${ }^{52}$ links the $\mathrm{N}$ issue with the climate boundary (anthropogenic $\mathrm{N}$ fixation uses large amounts of fossil fuel energy) and human demand for food. Both Rockström et al. and de Vries et al. agree that humanity has pushed the $\mathrm{N}$ cycle beyond a safe operating space boundary and that better nutrient management is essential for global sustainability.

Rockström and colleagues proposed a boundary for perturbation to the $\mathrm{P}$ cycle in terms of the annual $P$ inflow to the world's oceans, which should not exceed 10 times the natural background weathering of P.

A deeper analysis of $\mathrm{P}$ and the water cycle by Carpenter and Bennett ${ }^{53}$ argues that Earth system thresholds involving land and freshwater ecosystems would have been exceeded well before the oceanic geochemical threshold is reached. They have suggested a suite of precautionary P boundary values. Since their analysis, there is now also consensus that humanity has pushed the P cycle into an unsafe space. This concern is heightened because $\mathrm{P}$ is essentially a non-renewable resource, so issues of long-term supply have important economic and human security implications too.

\footnotetext{
${ }^{50}$ Sutton et al. (2013) Our Nutrient World. International Nitrogen INitiative/Global Program for Nutrient Management and NERC Centre for Ecology and Hydrology, UK. Available from www.unep.org.

${ }^{51}$ Human perturbation of global $\mathrm{N}$ and $\mathrm{P}$ cycles was systematically assessed by the international community in the 1980s and 90s: GESAMP (1987). Land/Sea Boundary Flux of Contaminants: Contributions from Rivers. Joint Group of Experts on the Scientific Aspects of Marine Pollution, Reports and Studies No. 32. UN/UNEP/FAO/UNESCO/WHO/WMO/ICMO/IAEA; GESAMP (1989). The atmospheric input of trace species to the world ocean. Reports and Studies No. 38. IMO/FAO/UNESCO/WMO/WHO/IAEA/UN/UNEP; GESAMP (1990). The State of the Marine Environment. Reports and Studies No 39, IMCO/ FAW/ UNESCO/ WMO/IAEA/ UN/ UNEP. Also, on linked N, P and C cycles: Garrels, R.M., Mackenzie, F.T., and Hunt, C. (1975), Chemical Cycles and the Global Environment. W. Kaufmann, Los Altos CA; MacKenzie, F.T. et al. (2002), Century-scale nitrogen and phosphorus controls of the carbon cycle. Chemical Geology 190, 13-32.

${ }^{52}$ de Vries, W. et al. (2013), Assessing planetary and regional boundaries related to food security and adverse environmental impacts, COSUST 5, 392-402.

${ }^{53}$ Carpenter, S. and Bennett, E. (2011) Reconsideration of the planetary boundary for phosphorus. Environmental Research Letters. doi: 10.1088/1748-9326/6/1/014009
} 


\section{The current state ${ }^{54}$}

Excess $\mathrm{N}$ and P are heterogeneously distributed around the world (figure 10) and have multiple drivers and impacts in agriculture, industrial production and global trade. Deliberate manufacture and application of $\mathrm{N}$ and $\mathrm{P}$ underpins present-day intensive agriculture, sustaining the world's human population. Humans currently convert over 120 million tonnes of atmospheric nitrogen to reactive forms such as ammonia and nitrates - more than all non-human processes combined 55 . Excess application is a severe problem in some areas, while other regions need nutrient replenishment to restore degraded lands or support productivity. Urbanisation, transport and heavy industry cause the diffuse emission of nutrient elements, leading to local and regional concentration of wastewater $\mathrm{N}$ and $\mathrm{P}$ pollution (nitrates, ammonia, phosphorus) and atmospheric N pollution (NOx, smog, brown haze, and the closely linked problems of black carbon and other climate-active pollutants).
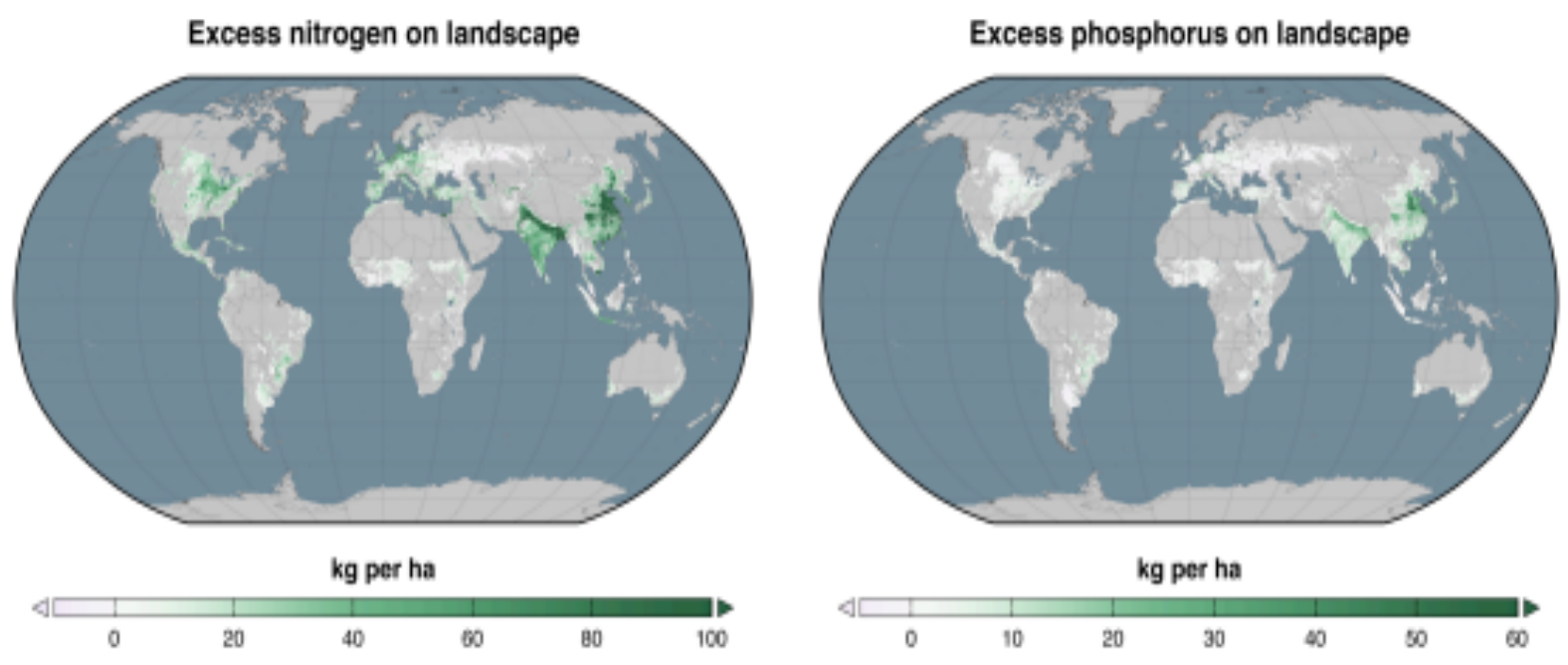

Figure 10 - Global distribution of excess $\mathrm{N}$ and P (Image from Foley et al. (2011), Solutions for a cultivated planet, Nature, 478(7369), 337-342.)

\section{Links to freshwater use, land use, and the atmospheric aerosol burden}

Managing nutrients is inseparable from the management of land, freshwater systems, and air quality.

Land use, primarily agriculture, is an important driver of both $\mathrm{N}$ and $\mathrm{P}$ cycle perturbation.

Freshwater bodies and the atmosphere are the recipients of excess nutrients and other forms of $\mathrm{N}$ and $\mathrm{P}$ pollution. The $\mathrm{N}$-containing gases NOx and ammonia are important chemical precursors to atmospheric aerosol formation, affecting local climate, hydrological cycling and ecosystems, and implicated in acid rain and soil acidification. There are no significant P-containing gases, although dust blown up into the atmosphere can make up a major proportion of aerosol particles, and also affect climate. Dust can contain large amounts of $\mathrm{P}$ and be transported large distances from its source regions (it is an important source of nutrients to remote marine ecosystems) ${ }^{56}$. Generally, the environmental effects of $\mathrm{P}$ tend to be more local than those of $\mathrm{N}$.

\footnotetext{
${ }^{54}$ The UNEP supported Global Partnership on Nutrient Management is an important science-policy resource for information on $\mathrm{N}$ and $\mathrm{P}$, their human sources and their environmental pathways: www.gpa.unep.org/index.php/global-partnership-on-nutrientmanagement

55 Galloway, J.N. et al. (2008). Transformation of the nitrogen cycle: recent trends, questions and potential solutions, Science 320 , 889-892.

${ }^{56}$ See the GESAMP reports, footnote 52.
} 


\section{The quality infrastructure for perturbed $N$ and $P$ biogeochemistry}

\section{Emerging awareness of the global problem}

Nutrients are only now being recognised as a global issue requiring global policy coordination. To date, the 'nutrient problem' has largely been seen as a fertilizer industry issue. However, links between nutrient cycles and energy use, along with a much wider range of industrial processes, are a rapidly emerging global policy concern. Nutrient releases interact in complex ways with biodiversity, climate change, and human health and food security (figure 11). These interactions are becoming a focus of increased research and monitoring.

Efforts to limit nutrient pollution have, to date, been undertaken primarily at the local and regional levels - for example, by limiting concentration of nitrate in groundwater or the emission of nitric oxides to urban environments. International legislation instruments for nutrient management include the UNECE Convention on Long-Range Transboundary Air Pollution (CLRTAP), the regional Marine Conventions, and the Convention on Biological Diversity.

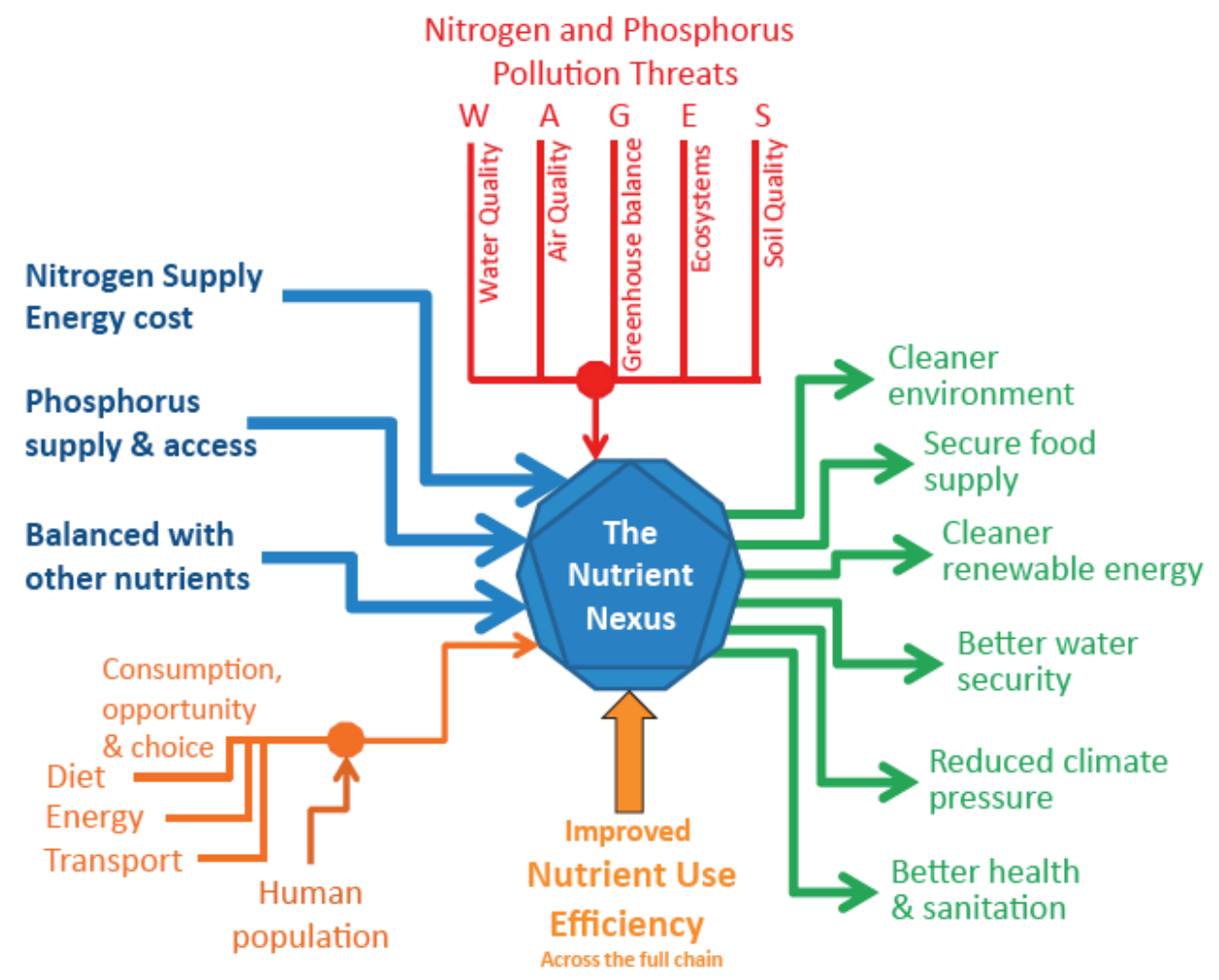

Figure 11 - The Nutrient nexus: a challenge for a global quality infrastructure.

(Figure reproduced from Sutton et al. (2013), Our Nutrient World, GPNM/INI/CEH.)

This focus on the local to regional scale, and on particular sectors relating to land and water pollution, means that there is a very well established quality infrastructure at these levels in industrialised nations. The picture is very different elsewhere in the world, and there are major knowledge gaps for understanding nutrient interactions in Earth system dynamics. 


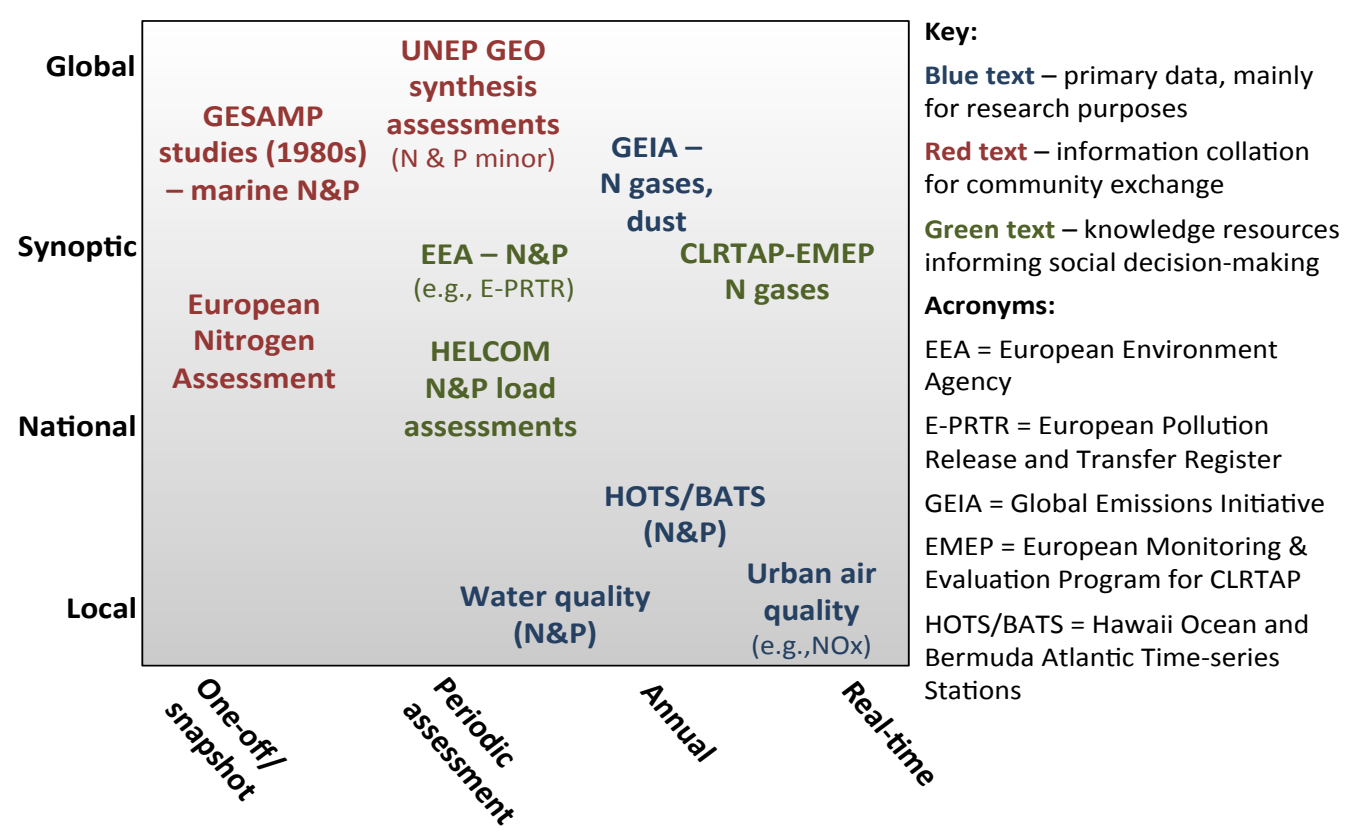

Figure 12 - An indication of the coverage of $\mathbf{N}$ and $\mathrm{P}$ information

\section{A complex data landscape}

Unlike the situation for climate and biodiversity, there has been no systematic global assessment of $\mathrm{N}$ and P. The magnitude of the data gap for such an assessment is known to be large, and it is also poorly specified. Discussions are underway between scientists, technologists and policy makers for a Global Nitrogen Assessment under the aegis of the International Nitrogen Initiative ${ }^{57}$.

At present, global data are scarce, and globally patchy. Methodological differences contribute to the current discrepancies in nutrient budgets. Biogeochemical cycles are complex, and studies typically address just part of the cycle. A particular challenge is that processes in these cycles operate at many rates, ranging from nearly instantaneous atmospheric photochemical reactions to the slow processes of rock weathering. $\mathrm{N}$ switches forms rapidly in the environment, so its measurements are not only spatially highly specific, but also temporally. This is often ignored when compiling data over space, and there is currently no adequate quality infrastructure for dealing with this complexity.

Nitrogen has received more attention than $\mathrm{P}$ because of its role in both water (eutrophication) and air quality problems. The biogeochemical cycle for $\mathrm{P}$, including its human perturbation, is arguably simpler than that of $\mathrm{N}$, so the data shortage is not as acute.

Key databases where methods and standards are well documented include:

- The Global Emissions Initiative (www.geiacenter.org), focused on observational data relating to interactions between climate and air quality. GEIA is currently addressing quality infrastructure issues through the development of an Emission Evaluation Clearinghouse, allowing for data inventory ensembles and improved data-model comparison and assimilation.

- The Emissions Database for Global Atmospheric Research (http://edgar.jrc.ec.europa.eu), an activity of the European Commission Joint Research Centre and the Netherlands Environmental Assessment Agency (PBL). EDGAR collates global data on several air pollutants including greenhouse gases and particulates/aerosols as well as $\mathrm{N}$ compounds, using an emissions factor approach. 
- The US Geological Society's periodic assessments of phosphate rock reserves and trade (http://minerals.usgs.gov/minerals/pubs/commodity/phosphate_rock)

- FAOSTAT (http://faostat3.fao.org/faostat-gateway/go/to/download/E/EF/E) provides statistics on fertilizer production, trade, environmental indicators, and some $\mathrm{N}$ emissions (e.g., $\mathrm{N}_{2} \mathrm{O}$, a potent greenhouse gas).

\section{$\mathrm{N}$ and $\mathrm{P}$ as integration challenges}

Apart from trends in the human drivers of change, and the evidence of local impacts, there is extremely limited information available relating to global processes, feedbacks and critical thresholds involving $\mathrm{N}$ and $\mathrm{P}$.

The present generation of Earth system models still have over-simplified representations of key biogeochemical cycles. Improvement in this process representation hinges on improved quality, quantity and coordination of observational and experimental data. The first stage of global process understanding is generally mapping the state of the world at various times.

One example of such an effort is the very useful World Resources Institute's Eutrophication and hypoxia map (www.wri.org/resource/interactive-map-eutrophication-hypoxia). This illustrates the data shortage challenge: the resource has had to be collated ab initio from literature, because there is no adequate accessible dataset.

As mentioned above, the nitrogen research community is mobilising new dialogues with business, the agriculture sector and policy in moving towards co-developing knowledge for action to address the emerging global nitrogen concerns. It is aligning and coordinating with existing international policy arenas (i.e., the CBD, CLRTAP and UNFCCC) as well as regional ones (e.g., European Commission's Water Framework Directive, Habitats Directive).

In contrast, institutional arrangements around the global phosphorus are highly fragmented, and still lack any deliberate international oversight ${ }^{58}$. Cordell (2008) points out that there are important geopolitical equity issues in the phosphorus context. The fertilizer industry is a highly concentrated one, with power held in a few large companies and their industry association. Uncontrolled markets pay no regard to people's rights to food. Countries such as the US, China and Morocco hold large reserves of $\mathrm{P}$, while rapidly developing and highly populated regions such as sub-Saharan Africa, India and Europe have minimal access to reserves and depend on imports.

The green arrows in Figure 11 are very familiar global development objectives, each with an established quality infrastructure (as discussed in depth for climate and biodiversity in this document). Quality infrastructure components for nutrient cycles need to be integrated with these existing systems, rather than reinvented.

\footnotetext{
${ }^{58}$ Discussed in Cordell, D. (2008) The story of phosphorus: missing global governance of a critical resource. http://phosphorusfutures.net/files/DCordell_SENSEpaper.pdf
} 
Table 6 - Summary of the state of the quality infrastructure on nutrient cycle perturbation

\begin{tabular}{|c|c|c|}
\hline QI element & Context & Issues \\
\hline Metrology & $\begin{array}{l}\odot \text { local scale, N \& P } \\
\text { regional and } \\
\text { global assessment, N } \\
\bigcirc \text { regional and } \\
\text { global assessment, P }\end{array}$ & $\begin{array}{l}\text { Established and tested techniques are in use for multiple } \\
\text { measures of biogeochemical processes and air and water quality } \\
\text { at local scales, e.g, EMEP/EEA air pollutant emission inventory } \\
\text { handbook, EC Directive on technical specifications for chemical } \\
\text { analysis and monitoring of water status. } \\
\text { Europe has produced a regional } \mathrm{N} \text { assessment (www.nine- } \\
\text { esf.org/ENA-Book), encountering measurement inconsistencies. } \\
\text { Analytical methods and data resources are not well-developed } \\
\text { for global assessment of biogeochemical processes of } \mathrm{N} \text { and P. }\end{array}$ \\
\hline $\begin{array}{l}\text { Standardization } \\
\text { and Conformity } \\
\text { assessment }\end{array}$ & $\begin{array}{l}\text { local and regional } \\
\text { policy contexts, N \& P } \\
\text { regional and } \\
\text { global scientific } \\
\text { assessment, N \& P }\end{array}$ & $\begin{array}{l}\text { Criteria and standards exist for air and water quality (e.g., US } \\
\text { National Ambient Air Quality Standards, WHO water quality } \\
\text { requirements). ISO standards for pollution prevention, waste } \\
\text { minimisation and laboratory competence are important in } \\
\text { controlling environmental N and P release at local level. Public } \\
\text { and environmental health laboratories have generally good } \\
\text { uptake of formal certification, accreditation and auditing. } \\
\text { Calls have been made for global N assessment, but heterogeneity } \\
\text { of issues and policies will make a global synthesis difficult to } \\
\text { carry out and validate. }\end{array}$ \\
\hline $\begin{array}{l}\text { Quality } \\
\text { Management }\end{array}$ & $\begin{array}{l}\odot \text { global N } \\
\bigcirc \text { global P }\end{array}$ & $\begin{array}{l}\text { Quality management developed for local pollution responses is } \\
\text { poorly suited to informing and supporting responses to global } \\
\text { dynamics of both } \mathrm{N} \text { and } \mathrm{P} \text {. Emerging risks (links between } \mathrm{N} \text { and } \mathrm{P} \\
\text { and global energy and food security) highlight knowledge and } \\
\text { governance gaps, especially for } \mathrm{P} \text {. General awareness of the } \\
\text { issues is low for both } \mathrm{N} \text { and } \mathrm{P} \text {. For } \mathrm{N} \text {, dialogues have begun to } \\
\text { link knowledge communities (industry, policy, science) and } \\
\text { enable policy integration (climate, biodiversity, pollution). }\end{array}$ \\
\hline
\end{tabular}

\section{Chemical pollution}

\section{The current state}

The growth of the world's economy is tightly linked with growth in chemical production, a close relationship that is projected to continue ${ }^{59}$. A wide variety of harmful substances is released into the environment, associated with all aspects of modern human activity: agriculture, pharmaceuticals, consumer products, technology, heavy industry, urbanization and transport.

The recent trend embeds a geographical shift in patterns of production and consumption, with rapid growth in developing countries, for domestic needs and international trade. This trend also embeds important social and economic issues: as supplies of high-quality raw materials are depleted in industrialized countries, energy- and pollution-intensive activities tend to shift to less developed countries, bringing risks of hazard and harm to new places. Chemical pollution is now a globally distributed concern, and concern is focusing on its systemic consequences ${ }^{60}$.

Concern is greatest 61 about the classes of compounds that are environmentally persistent, bioaccumulative, and toxic, because these have global reach regardless of where they are released. From an Earth system perspective, these kinds of substances of concern include

\footnotetext{
${ }^{59}$ Organisation for Economic Development (2012). OECD Environmental Outlook to 2050: The Consequences of Inaction. OECD, Paris. ${ }^{60}$ UNEP (2012) Global Chemicals Outlook. www.unep.org/chemicalsandwaste/Portals/9/Mainstreaming/GCO/GCO_SynthesisReport_UNEP.pdf

${ }^{61}$ The ChemSec SIN List, www.chemsec.org/what-we-do/sin-list; EU REACH Regulation,

http://ec.europa.eu/enterprise/sectors/chemicals/reach/index_en.htm; UNEP (2012) Global Chemicals Outlook, and UNEP (2013)
} 
- reproductive and developmental toxicants and carcinogens, because of their effects on the health of living organisms and their capacity to perturb the fundamental functioning of ecosystems; and

- substances that alter Earth's physical processes, such as climate-active greenhouse gases and stratospheric ozone depleters.

Enough is already known about the general properties of these compound classes to enable precautionary measures and sound management approaches to be set in place worldwide. The rise in hazardous, bioaccumulating and persistent compounds presents multi-scale risks to organisms (including human beings), ecosystems and even planetary functioning, as the 20th century $\mathrm{CFC} /$ ozone depletion problem showed.

Rockström and colleagues highlighted stratospheric ozone depletion as a chemical planetary boundary in its own right: emissions of long-lived synthetic CFCs had already crossed a planetary threshold, reacting in the upper atmosphere over polar regions to destroy ozone. They proposed a global boundary of no more than a 5\% reduction from pre-industrial ozone concentrations (290 Dobson Units). For other chemical pollution, they were not able to propose a single aggregate quantitative boundary.

Persson and colleagues 62 argue that the complexity of chemical production and use, and of biophysical processes, mean that there is no single chemical pollution planetary boundary. They propose that chemical pollution is not an issue where risk can be precisely characterized. Instead, policies need to recognise ignorance and uncertainty. Chemical pollution planetary boundary threats to prioritise are those where vital Earth system processes can be affected, in irreversible ways, recognizing that global effects might not be evident until the unwanted impacts are already in play. Persson and colleagues set out the practical implications of these features for precautionary governance and for chemicals hazard assessment (as opposed to risk assessment).

\section{Links to freshwater use, land use, and the atmospheric aerosol burden}

Chemical pollution is a major issue influencing the management of land, freshwater systems, and air quality. Land uses - urbanization, infrastructure, and modern agriculture - are key drivers of current trends of chemical pollution. Chemical pollution may be released directly into watercourses and the atmosphere, or arrive there indirectly through runoff or windblown material from land surfaces.

Some forms of gaseous chemical pollution can undergo reactions in the atmosphere and become aerosols. Volatile organic compounds are produced in industrial and combustion processes (there are also natural biogenic sources). They react in sunlight with NOx and other $\mathrm{N}$ containing gases to form aerosol particles (seen as haze or smog), as well as generating ozone close to ground level. At high altitude, ozone is beneficial to life because of its interaction with the UV radiation from sunlight. At ground level it is a problem, because it is highly toxic to living organisms.

Human activities have altered the natural patterns of aerosol formation - deforestation reduces the biogenic aerosol over some regions, while urbanization increases anthropogenic aerosol in others. The link between aerosol, climate, water and ecosystems are highly complex, and are still poorly represented in quantitative models. This is one reason why Rockström and colleagues were not able to propose a planetary boundary for aerosols.

Costs of Inaction

www.unep.org/chemicalsandwaste/Portals/9/Mainstreaming/CostOfInaction/Report_Cost_of_Inaction_Feb2013.pdf .

62 Persson, L. et al. (2013) Confronting unknown Planetary Boundary threats from chemical pollution, Environmental Science \&

Technology, 47 (22), 12619-12622. http://pubs.acs.org/doi/full/10.1021/es402501c 


\section{The quality infrastructure for global chemical pollution}

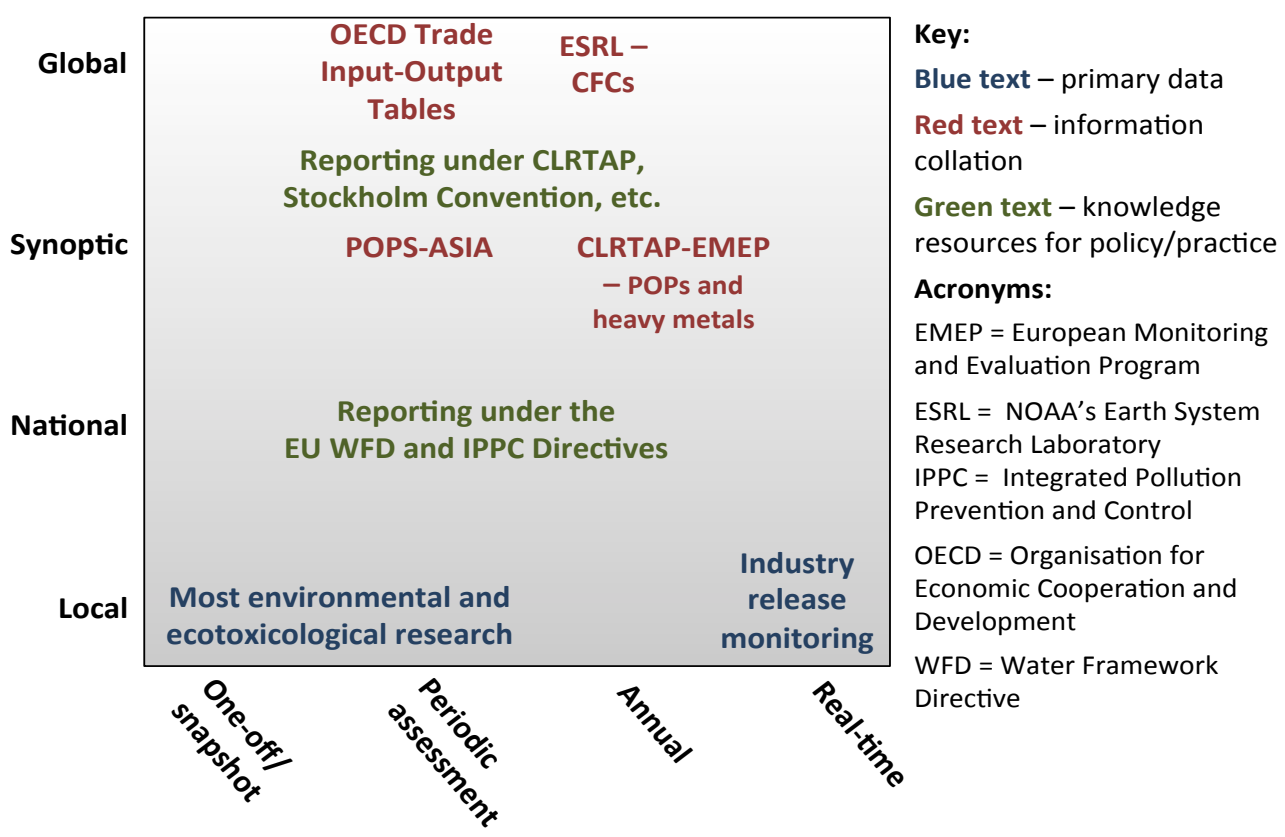

Figure 13 - Coverage of the environmental quality infrastructure for chemical pollution

The quality infrastructure differs sharply between the processes relating to the production of substances of high concern, and those relating to the environmental pathways and receptors in land, air and water systems.

At the production end, industry interests play a defining role that is not the same as for the other global environmental processes discussed in the earlier sections. In the developed world, chemical production is among the most highly regulated and quality assured processes, but also one that is also subject to tight commercial confidentiality conditions. This means that the metrology, standardization and conformity dimensions of the quality infrastructure are highly advanced, but there is a tendency for the external engagement, learning and precautionary aspects of quality management to be lacking.

Earth system impacts of the chemicals being produced are a very new and often controversial consideration; controls are currently informed by analysis of ecotoxicological and public health impacts of individual substances and classes of compounds, not systemic impacts. Many controls are in place for chemical releases at the local level, for specific classes of compounds. There are some global policies on chemicals (such as the Stockholm Convention on Persistent Organic Pollutants, and the Montreal Protocol of the Vienna Convention, which deals with ozone-depleting CFCs), but these have come into place well after a substance has become a global problem. The majority of chemical legislation and regulation is local or regional. Efforts such as the new European REACH regulations 63 are being made to list and control the trade and management of individual compounds with the most severe effects, but these are not yet effective globally, and banned chemicals are still traded and transported around the world in significant quantities. Tens of thousands of chemicals are registered on the market, and hundreds of new chemicals are introduced into commerce every year. Companies are required to declare new substances that are likely to cause harm to the environment or public health, but the assessment of that likelihood rests largely with the companies themselves. In some developing countries, regulatory and management instruments remain weak. Policy and scientific gaps hinder chemicals registration, sound management, compliance and monitoring ${ }^{64}$.

\footnotetext{
${ }^{63}$ The European Union's Regulation Registration, Evaluation, Authorisation and Restriction of Chemicals (REACH), http://ec.europa.eu/enterprise/sectors/chemicals/reach/index_en.htm. the ${ }^{64}$ UNEP (2012) Global Chemicals Outlook; UNEP (2013) Costs of Inaction.
} 
Forums exist for expert dialogue between industry, academia and policy about the production and use of chemical substances, such as:

- The UN ECOSOC Committee of Experts on the Transport of Dangerous Goods and on the Globally Harmonized System of Classification and Labelling of Chemicals (www.unece.org/trans/danger/danger.html), which aims for improved global coordination, but does not have an environmental protection remit.

- Professional institutes such as the American Chemical Society (www.acs.org), the Gesellschaft Deutscher Chemiker (www.gdch.de) and many other national institutes, which also provide accreditation and certification for scientists in industry and in academia.

- The Society for Environmental Toxicology and Chemistry (www.setac.org), which supports the development of principles and practices for sustainable environmental and ecological management.

At the other end of the chemicals chain lies the management of chemical risks once substances are in the environment. Like climate and biodiversity loss, there are formal science-policy arenas addressing chemical risks, but unlike them, there are multiple arenas treating different aspects of the problem. This presents a fractured governance landscape, characterized by many data-gathering initiatives facing the challenge of making a coherent picture out of a nearly infinite number of chemicals, contexts and environmental or health consequences. The data management and quality control infrastructure for existing initiatives are typically excellent, benefiting from the high degree of regulation, standardization and compliance that is normal for the sector plus the strength in international environmental research and policy coordination that has been built up over recent decades.

However, there are serious gaps and shortcomings, when viewed from a planetary perspective.

The vast majority of the necessary data relating to chemical production is unavailable to users and environmental managers outside industry, especially outside the most industrialized nations ${ }^{65}$. Environmental metrology is hampered by the diversity of synthetic chemicals, the processes for creating them, and the uses to which they are applied. Multiple approaches to hazard classification and chemical categorization are used in parallel, with limited scope for interoperability66. Different national legislations deal with different compounds, their production, doses and uses in very diverse ways. Measurement, monitoring and regulation is also made difficult by the fact that chemicals react in the environment - and the toxicity of the reaction products may be unknown. Some substances are seen in the environment in the same form as they were made, but most undergo a chemical transformation ${ }^{67}$, which will vary according to environmental conditions.

As chemical pollution becomes recognised as a global problem, the global fragmentation of information is recognised as a serious problem. Europe and North America have effective, very similar infrastructures, driven by their shared commitments under the Convention on Long-Range Transboundary Air Pollution (CLRTAP). This can now be regarded essentially as a hemispheric convention, as its 51 signatories are contiguous across Eurasia and North America. It covers several families of substances of high concern, and has been expanded to include new ones as environmental risks manifest themselves. Examples of CLRTAP-linked information agencies include:

- The European Database for Atmospheric Composition Research (http://ebas.nilu.no) which handles, stores and disseminates atmospheric data generated by many international and

\footnotetext{
${ }^{65}$ Almeidal, F.V. et al. (2007) Substâncias tóxicas persistentes (STP) no Brasil, Química Nova 30 (8) http://dx.doi.org/10.1590/S0100-40422007000800033.

${ }^{66}$ Swanson, M.B. et al. (1997) A screening method for ranking and scoring chemicals by potential human health and environmental impacts. Environmental Toxicology and Chemistry 16 (2), 372-383; Pennington, D.W. and Bare, J.C. (2001) Comparison of chemical screening and ranking approaches: the waste minimization prioritization tool versus toxic equivalency potentials. Risk Analysis 21(5), 897-912.

${ }^{67}$ European Environment Agency (2011) Hazardous substances in Europe's fresh and marine waters: An overview. EEA Technical Report 08/2011.
} 
national frameworks such as long-term monitoring programmes and research projects. It serves the European Monitoring and Evaluation Program (EMEP), the Global Atmosphere Watch, World Data Centre for Aerosol, the OSPAR and HELCOM Conventions, and other frameworks.

- EMEP (www.emep.int) coordinates regular laboratory intercomparisons. Over 30 rounds have been carried out, with data and reports available on

www.nilu.no/projects/ccc/intercomparison/info.html.

Much of the world still lacks adequate data, policy, monitoring systems and enforcement mechanisms. The experience of POPS-Asia illustrates the challenges. The Stockholm Convention on Persistent Organic Pollutants came into force in 2004. A decade later, a UNEP and GEF-supported multi-government public information resource, the POPS-Asia Warehouse (www.pops-asia.org) now exists, but it still lacks much of the key data. Information remains local or national, as problems have become regional and global. Box 5 outlines the Arctic Council's environment and sustainability coordination activities for the Arctic, an example of a large regional initiative.

There is growing evidence of accumulation of ecologically incompatible persistent chemicals, complex pathways of exposure and "cocktail effects" 68 . This is a very pressing knowledge gap, especially in the context of climate change and other environmental risks ${ }^{69}$. This points towards a strongly precautionary 'principle of zero discharge'70. This could be achieved through widened engagement of business with existing quality infrastructure tools for sound chemicals management; transformed reporting and intensified monitoring; and a learning approach to environmental management oriented towards identification of alternatives rather than allocation of permits to pollute.

\footnotetext{
${ }^{68}$ UNEP (2013) Global Chemicals Outlook, and discussions on the European Commission DG Environment 'Combination effects of chemicals', http://ec.europa.eu/environment/chemicals/effects/effects_en.htm

${ }^{69}$ Balbus, J.M. et al. (2013) Implications of global climate change for the assessment and management of human health risks of chemicals in the natural environment. Environmental Toxicology \& Chemistry 32, 62-78.

70 Thornton, J. (2000). Beyond risk: an ecological paradigm to prevent global chemical pollution. International Journal of Occupational and Environmental Health 6, 318-330.
} 
Table 7 - Summary of the state of the quality infrastructure on chemical pollution

\begin{tabular}{|c|c|c|}
\hline QI element & Context & Issues \\
\hline Metrology & $\begin{array}{l}\odot \text { Industrial production and supply } \\
\text { Є Environmental assessment }\end{array}$ & $\begin{array}{l}\text { Established and tested techniques exist for } \\
\text { chemical substances of high concern. Globalised } \\
\text { and concentrated industry means much of the } \\
\text { world has adequate metrology at the production } \\
\text { end. } \\
\text { Number of substances and lack of knowledge } \\
\text { about new chemicals, mixtures and } \\
\text { environmental pathways presents measurement } \\
\text { challenges. Quality issues hamper management } \\
\text { of legacy and emerging chemicals. }\end{array}$ \\
\hline Standardization & $\begin{array}{l}\ominus \text { Industrial production and supply } \\
\odot \text { Environmental assessment }\end{array}$ & $\begin{array}{l}\text { Chemicals and industrial production sectors } \\
\text { apply international standardization for many } \\
\text { relevant processes and environmental } \\
\text { management systems. Chemicals associations } \\
\text { are present in most regions. } \\
\text { Multiple contexts and changing suite of } \\
\text { substances of concern mean that environmental } \\
\text { assessments may lack comparability, consistency } \\
\text { and interoperability. }\end{array}$ \\
\hline $\begin{array}{l}\text { Conformity } \\
\text { assessment }\end{array}$ & $\begin{array}{l}\text { (U) CLRTAP region } \\
\text { Ø Most of the rest of the world }\end{array}$ & $\begin{array}{l}\text { Global conformity agreements exist for } \\
\text { transport, labelling, and classification. Apart } \\
\text { from selected chemicals in the northern } \\
\text { hemisphere, conformity agreement and } \\
\text { assessment are very weak for use, release, } \\
\text { hazard response, and many other aspects of } \\
\text { environmental risk. }\end{array}$ \\
\hline $\begin{array}{l}\text { Quality } \\
\text { Management }\end{array}$ & Policy is reactive, not proactive & $\begin{array}{l}\text { Quality management developed for local } \\
\text { pollution responses is poorly suited to informing } \\
\text { and supporting responses to global dynamics and } \\
\text { emerging risks. } \\
\text { Society's access to global information and lower } \\
\text { tolerance of chemical pollution is an important } \\
\text { force for positive change. } \\
\text { Dialogues between knowledge communities } \\
\text { (industry, policy, science) are fragmented and } \\
\text { show power imbalances. }\end{array}$ \\
\hline
\end{tabular}




\section{Box 5 - Regional coordination of knowledge for action - reflections on the Arctic quality infrastructure}

The Arctic system presents the clearest symptoms of global environmental change, with known feedbacks (e.g. ice-albedo) and threshold dynamics. It already is a region showing clear stresses in many of the planetary boundary processes, including high regional climate warming, ocean acidification, chemical pollution, biodiversity loss and ecosystem changes. Stresses are also evident to the regional economic and societal stability.

In 1996, the Arctic Council formed, bringing together the Arctic States to tackle issues of sustainable development and environmental protection. The Council is structured in six Working Groups, and their research focuses on biodiversity, marine ecosystems, the environment and climate and on Arctic people. Each Working Group has a clear mandate, and produces assessment and monitoring reports at regular intervals.

Quality infrastructure at higher levels of information and knowledge is maintained through participatory processes (including traditional knowledge, modelling data and measured data), large scientific collaborations and critical peer review. This infrastructure lies in the design of the working groups, their goals and activities.

At the lower levels of the pyramid - i.e. in the realm of data collection, manipulation and access - the quality infrastructure is specific to each working group. Data reporting, sharing and standardization platforms are mostly still in development. They are the product of a response to a need for coordination, rather than a backbone pre-designed in the research process. These platforms include a data-sharing platform named ArcticData; the Arctic Spatial Data Infrastructure (Arctic SDI) designed to collate spatially referenced data for the Arctic; and the Sustained Arctic Operating Network (SAON), set to 'achieve long-term Arctic-wide observing activities that provide free, open, and timely access to high-quality data that will realize pan-Arctic and global value-added services and provide societal benefits.'

One of the Arctic Council Working Groups, the Arctic Monitoring and Assessment Program, prepares assessment reports on different aspects of Arctic social and environmental change. Its 2009 State of the Environment report for Arctic Pollution is one of the most systematic state-of-the-art assessments of regional pollution in the world. It highlights several issues experienced elsewhere:

- 'There is little information on the routes of exposure or trends of contaminants in Arctic populations' (summary, p. viii)

- 'A lack of information [on POPs mixtures and emerging compounds] is limiting human health risk assessment' (recommendations, $\mathrm{p} . \mathrm{x}$ )

- $\quad$ 'There is a paucity of information on the geographic distribution of fluorinated compounds...' (p. 19)

- 'The ability to make comparisons across both time and space is made possible by coordination of research and by rigorous quality assurance/quality control standards.' (p. 48)

Muir and de Wit concisely outline recommendations to address these issues in Arctic environmental change. They highlight the need for laboratory intercomparisons; improved use of data and models in combination; improved archiving, especially for biological effects in addition to contaminant trends; and improved quality assurance, especially for new contaminants.

Information resources:

www.arctic-council.org; http://arcticdata.is; http://arctic-sdi.org; www.arcticobserving.org

AMAP (2009) Arctic Pollution 2009 - AMAP State of the Environment Report. Arctic Monitoring and Assessment Program, http://amap.no.

Muir, D.C.G. and de Wit, C.A. (2010) Trends of legacy and new persistent organic pollutants in the circumpolar arctic: Overview, conclusions, and recommendations. Science of the Total Environment. 408, 3044-3051. 


\section{Global measurement as a sustainability issue}

\section{Building worldwide capacity and infrastructure for global change metrology}

\section{What is the required scope?}

The planetary boundaries framework includes fundamental Earth system processes (climate change, the functioning of ecosystems and biodiversity, and biogeochemical cycles, shown in Figure 14 as dynamically linked) and also human drivers of change in these processes (land use, freshwater use, altered atmospheric properties and the release of chemical pollution). These issues are a core set of biophysically framed processes underpinning global sustainability. An effective quality infrastructure for global sustainability needs to address these issues in ways that reflect local realities and also track the overall global phenomena.

In this report, we have focused on the shaded items in Figure 14, because these are the issues where global policies exist (climate and biodiversity) or where globally emergent concerns are leading to calls for greater global coordination (biogeochemistry and chemical pollution). The unshaded item, human resource use, is arguably more directly and concretely linked to people's lived experience of global sustainability.

A challenge for metrology and quality infrastructure is that all the issues within the human resource use category are locally specific, less globally generalizable than the biophysical measures, and subject to a complex web of local, national and regional decision-making processes. Some aspects of these issues can be observed at the global level (e.g., Earth observations of land cover and water systems), but these observations still require an immense interpretation effort in order to provide meaningful information about local processes, beyond core biophysical properties.

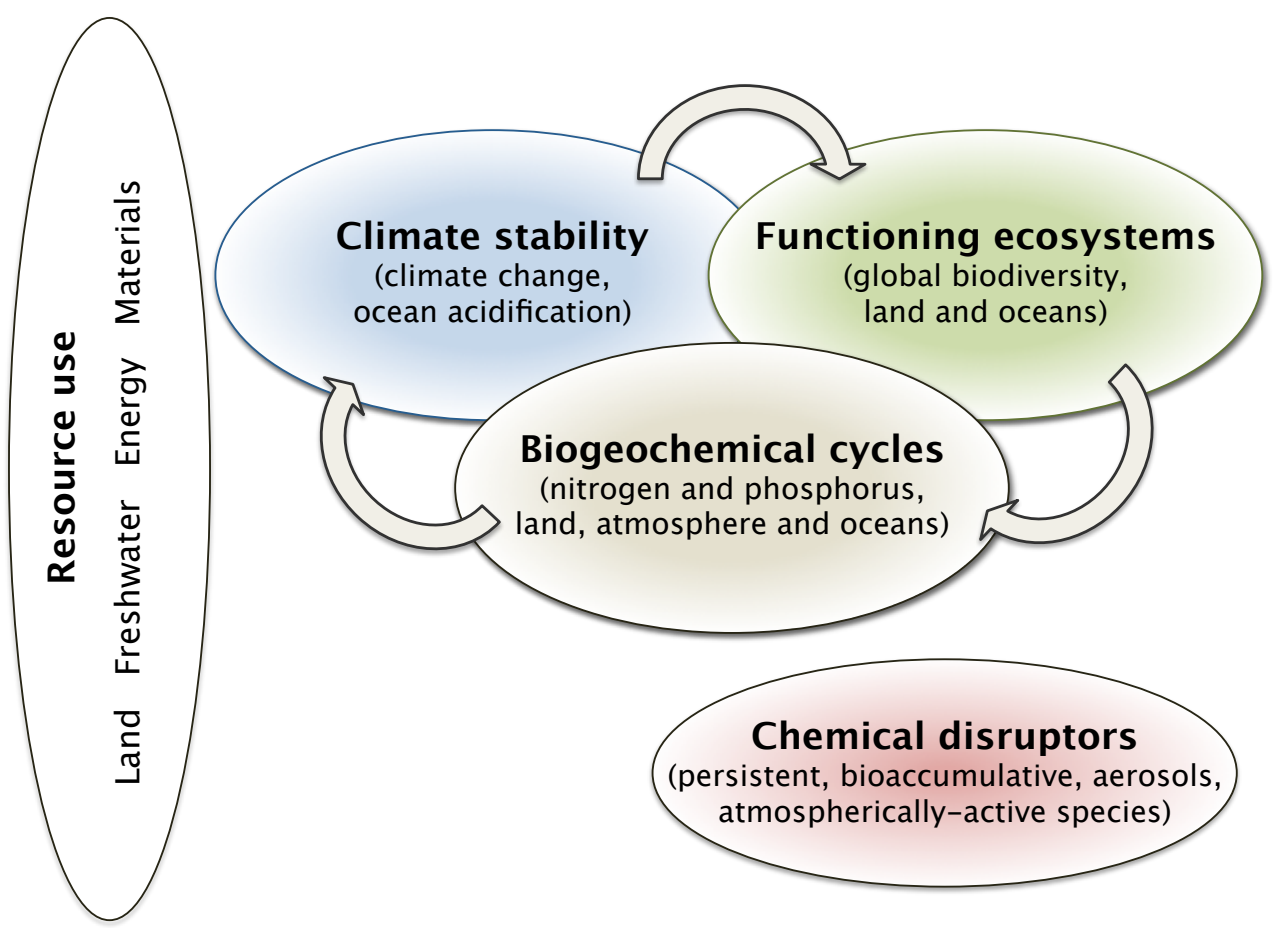

Figure 14 - Critical global processes for sustainability. Human use of natural resources and the release of disruptive chemical pollution affect the fundamental Earth system dynamics of climate, ecosystems and biogeochemical processes. 
The biophysical framing of the planetary boundaries concept therefore needs to be complemented by attention to the human dimensions of sustainable development. The most well known effort in this regard is the 'Oxfam doughnut' framework, which focuses explicitly on social justice principles underpinning sustainability. In this framework, Raworth ${ }^{71}$ extends the planetary boundary concept to social objectives, using criteria identified from the social priorities that were most frequently articulated in national statements submitted to the UN system ahead of the Rio+20 Earth Summit. These criteria were:

$\begin{array}{ll}\text { - } & \text { Food security } \\ \text { - } & \text { Wncome } \\ \text { - } & \text { Health care } \\ \text { - } & \text { Education } \\ \text { - } & \text { Energy access }\end{array}$

- Food security

- Water and sanitation

- Education

Energy access
- Gender equality

- Social equity

- Voice

- Jobs

- Resilience

Raworth suggests that indicative metrics for almost all of these issues already exist, in the statistics functions of FAO, the World Bank, the UN and similar organisations. The current state of these measures can be displayed against policy targets, in a social deprivation gap dashboard. Combining this visual summary of social justice issues with the planetary boundaries biophysical 'safe operating space' provides an easily graspable overview of global sustainability.

One potential next stage of development of the planetary boundaries and 'doughnut' concepts is to address the dynamic relationships between human beings and nature, going beyond the descriptive approach that is currently possible. This would needs to focus on the drivers and impacts of biophysical change: a complex mixture of social, cultural, economic, political and ethical dimensions of resource use.

The current Sustainable Development Goals process is showing that progress has already been made in such an integrative perspective. There is no shortage of indicators to choose from, to measure progress against the eventual goals and targets. But the SDG process is also showing that as this integrative perspective opens new horizons for research, policy and development cooperation, the quality infrastructure will also require adjustment and expansion ${ }^{72}$.

Just as for biophysical change processes, data gaps exist in global coverage of many human dimensions of global change, except for basic social and economic variables. Information remains in 'silos'. There is very little synchronous and collocated measurement of social and biophysical data, which is necessary for understanding and managing human-environment interactions. Measures are almost entirely lacking of less concrete but no less important factors, such as wellbeing, participation, fairness, and cultural perceptions. These issues lie at the heart of sustainability and have direct (albeit complex) relationships to the ecosystems within which human beings live.

\section{Lessons from a pioneer initiative}

Some of the best examples of the creation of a global infrastructure for global environmental change date back several decades. The 1972 Stockholm UN Conference perhaps marks the key milestone when sustainability becoming a global issue. By the 1980s, it had become evident that global change processes needed to be tracked, quantified, and modelled. The political and economic conditions were right to support the creation of international cooperative global change research programs to coordinate this scientific effort for climate and biogeochemical sciences. Much of this report has highlighted problems in coordination and data coverage as a wider set of issues emerge as global

\footnotetext{
${ }^{71}$ Raworth, K. (2012). A Safe and Just Operating Space for humanity: Can we live within the doughnut? Oxford. Oxfam Discussion Papers.

72 'Securing reliable data for development', UN DESA Statistics.Division.

www.un.org/en/development/desa/newsletter/desanews/feature/2014/03/index.html, accessed 28 April 2014.
} 
concerns. It is illuminating to take a backward look at lessons learned (and fortunately for us, well documented) from one of these pioneer examples, the Joint Global Ocean Flux Study (1987-2003) ${ }^{73}$.

The JGOFS project started as a small US-led part of the World Climate Research Program's (WCRP) World Ocean Circulation Experiment. A team of scientists recognized that the systems being put in place to measure and monitor ocean physical processes presented a unique and important opportunity to also measure biogeochemical processes. Several countries were already engaging in small-scale flux studies measuring the exchange of gases and essential elements between oceans, sediments and the atmosphere. Determining global net fluxes and understanding the processes controlling them was beyond the capability of any one nation. The project grew into an international initiative funded cooperatively through many national research and network funding streams ${ }^{74}$, and became one of the flagship activities of the newly formed International Geosphere-Biosphere Program (IGBP).

Several features of this experience resonate with the quality infrastructure development issues facing emergent global change issues today:

- Starting with opportunism (biogeochemistry using physical sciences infrastructure) and evolving into strategic cross-disciplinary coordination is possible.

- Starting with dialogue between communities is important, to define scope and ascertain the actual interests of all potential stakeholders, to resolve 'disciplinary turf wars' and to make best use of investment and people resources.

- Starting with local studies, a global picture can develop but it requires on-going coordination of research priorities, resource allocation and information sharing processes.

- Some kind of agency is needed to provide a vetting role for global, coordinated science. For JGOFS it was a committee of national scientific academy board members. The global change programmes WCRP and IGBP took on that role through the life of JGOFS and its follow-on studies. These programmes are currently being reconfigured into Future Earth ${ }^{75}$. This report has highlighted other key 'vetting' forums linked to the IPCC process and the newly formed IPBES.

- A focus on methods, data, techniques, intercomparison and interoperability is needed through the life of an initiative.

- Especially in research, the needs for programmatic infrastructure are frequently underestimated, hampering people's access to the information that is produced in the programme.

- Metadata (organised temporally and geographically) is critical for functional crossdisciplinary, multiscale global change research informing action. It is a time-consuming but essential process, requiring on-going dialogues across the data producer and data user communities. 'Technology is good, people are more important'. 76

- When the system itself is changing, data systems need to balance existing and new technologies, informed by data system experts and active investigators.

In his reflections on JGOFS at the programme's final science conference in 2003, senior scientist Jim McCarthy said that the most important lesson learned was that

'More than we ever could have imagined two decades ago, today the world really needs the science that has been advanced by JGOFS'77.

This is what still motivates most global change scientists and practitioners today.

\footnotetext{
${ }^{73}$ Information obtained from JGOFS reports http://ijgofs.whoi.edu; Scientific Committee for Oceanic Research, 1988. The Joint Global Ocean Flux Study. Report of the first session of the SCOR Committee for JGOFS.

${ }^{74}$ Marine Data \& Information Management - Lessons from JGOFS, SCOR/IGBP Meeting on Data Management, December 2003.

75 www.futureearth.info

${ }^{76}$ Chandler, 2005. JGOFS Data Management Lessons Learned, www1.whoi.edu/datasys/talks/JGOFS_DM_LL.ppt

77 http://ijgofs.whoi.edu/Final_oSC/McCarthy.pdf
} 


\section{What is 'good enough' measurement?}

In this report, we have often expressed concern about the shortcomings in the quality of global data. It is important to emphasise that there has never been a better knowledge base; by any objective measure there is a wealth of global data to inform action. The challenge is that as more data are produced, and more data-gathering systems become possible, the baseline of expectations and the demand for ever-improved resolution and coverage rise.

Specifying quality requirements for global data is therefore an evolving process, shaped by both data producers and data users, in multiple fields of research, policy and practice. We return to our key tenets of knowledge for global sustainability action, to outline how they help to define what is 'good enough' measurement.

Global sustainability requires global knowledge: Good enough knowledge at the global level must mean extensive, representative and inclusive participation, in both data provision and in the decision-making processes about what information and actions are needed. A quality infrastructure must include worldwide mechanisms for collectively defining data quality criteria and setting priorities for information gathering. These mechanisms are needed internally within a given knowledge community (such as independent scientific peer review processes) and externally, to ensure exchange among different knowledge communities (such as quality assurance principles and ISO standards).

Global sustainability requires effective responses to global risks: A precautionary approach accepts that a 'one size fits all' approach is rarely appropriate to resolving complex socialenvironmental problems. Global goals need to be congruent with local knowledge and action. Effectiveness and resilience therefore hinge on including a diversity of perspectives, multiple sources of information, and multiple options for responses. However, engaging with and bridging across different knowledge communities presents challenges. Decisions need to be made about the validity of different knowledge inputs, and the depth and extent of participation. Good governance requires that these processes are inclusive, transparent, legitimate and accountable.

Global sustainability entails living with uncertainty. Adaptive governance, capable of making provisional choices and actions, is key to managing dynamic changes in a resilient way. Resilience analysis seeks to understand social and biophysical systems as linked, interdependent systems. Linked social-environmental systems are subject to thresholds and cross-scale interactions, where not all changes are gradual, reversible or predictable. 'Good enough' measurement, in this context, involves system monitoring, rather than just tracking fixed metrics ${ }^{78}$. Adaptive approaches require improved ways of defining and maintaining standards in contexts of changing baselines. They require learning processes alongside quality control processes (similar discussions are evident in the field of innovation ${ }^{79}$ ).

\section{Handling Uncertainties}

The planetary boundaries were proposed because of rising concern about global environmental risks linked to the human perturbation of Earth system processes. These processes involve many kinds of uncertainty - in fundamental process understanding, in measurement, in their intrinsic complexity, and with regard to human choices about interventions in the processes.

Many of the most pressing challenges for uncertainty analysis in the context of global environmental change relate to the human dimensions of the risks - both in terms of causing those risks by choices that set particular processes in motion, and in terms of experiencing the consequences. However, risk assessment is still too often treated as a technical exercise in quantification of biophysical hazard and financial exposure.

\footnotetext{
${ }^{78}$ One widely used example is the Conservation Measures Partnership's Open Standards for the Practice of Conservation, www.conservationmeasures.org/wp-content/uploads/2013/05/CMP-OS-V3-0-Final.pdf

${ }^{79}$ e.g., Bossink, B.A.G. (2002). The strategic function of quality in the management of innovation. Total Quality Management, 13(2), 195.205. http://ideas.repec.org/p/dgr/vuarem/2002-22.html
} 
The real risks to people arise from a complex function of the dynamics of the natural world and of society, and indeed of the human mind, with its desires, fears and anticipations. An improved understanding of the multiple interrelationships between the natural and social realms is needed. 80 .

Emerging research into risk and uncertainty therefore focuses on the interface between society and the natural environment. Research at this interface has a dual motivation: to develop greater understanding of our changing environment and the associated risks, and to inform real-world action in the face of human-caused change. This presents new challenges, requiring deeper interdisciplinarity, using methods that consider integrated socio-technical and socio-environmental systems.

At these interdisciplinary interfaces, it has become evident that methods for analysing uncertainty themselves need to evolve. Environmental risk analysts categorise uncertainty in various ways (Figure 15). Broadly, epistemic uncertainty relates to the lack of knowledge about the system. Obtaining more data is an important means of enabling more accurate and precise understanding of the processes in question. Epistemic uncertainty can therefore be reduced.

Complex systems are often characterised by inherent, irreducible variability. For instance, El Niño/La Niña events are very distinct states of the regional climate of the Pacific Ocean, which oscillate periodically, but irregularly. Aleatory uncertainty is the uncertainty relating to this kind of stochastic pattern. Increasing the observation base of such a system will help to characterise the uncertainty, but will not necessarily reduce it. In other words, a shift in such a system may not become predictable in terms of precisely when or where a change will happen, although it may be highly certain that the system will change from one state to another, and the causal mechanisms may be well understood.

In global change research, human choice is often bundled in with aleatory uncertainty. Scenarios are often described as one approach of dealing with uncertainty in this way ${ }^{81}$. Done well, they can certainly help in characterising the options for change. However, global sustainability involves human choices. We are unaccustomed to thinking of the Earth system as a purposeful system, but the planetary boundaries concept highlights the fact that human choices and action are changing the world in particular ways. This suggests that an additional category of uncertainty needs to be recognised - that associated with human choice and agency.

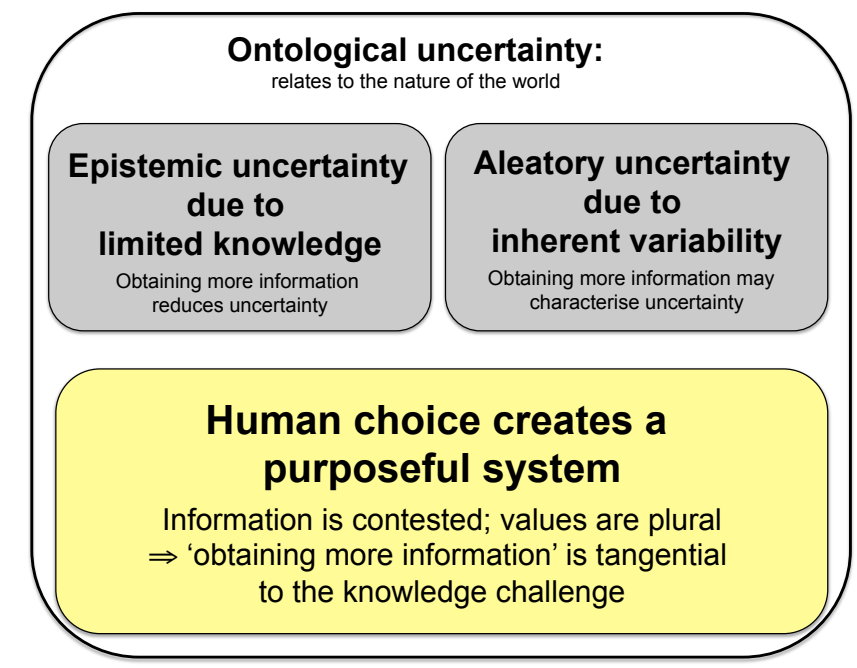

Figure 15 - Different kinds of uncertainty about environmental change and risk require different kinds of response

\footnotetext{
${ }^{80}$ Rougier, J. et al. (2013) Risk and uncertainty assessment for natural hazards. Cambridge University Press. www.cambridge.org/nl/academic/subjects/earth-and-environmental-science/environmental-science/risk-and-uncertaintyassessment-natural-hazards. This book addresses both social and biophysical aspects of uncertainty assessment.

${ }^{81}$ Lissner, T.K. et al. (2014), Climate impacts on human livelihoods: where uncertainty matters in projections of water availability, Earth System Dynamics Discussions, 5, 403-442, www.earth-syst-dynam-discuss.net/5/403/2014
} 
By bundling epistemic, aleatory and human-agency uncertainties together, we risk not focusing activities to assess and manage the uncertainty where they are actually needed. Issues of choice and human agency bring a different dimension of uncertainty, which is coming increasingly to the fore as the predictive power of the scientific dimensions of risk assessment grows. If the issue is one of human choice, improving the technical aspects of the quality infrastructure and obtaining (additional, more finely resolved) data will not necessarily make any difference to the outcomes in the real world.

A theme recurring throughout this report is the role of social learning in responding to global environmental change. The role of knowledge, learning and participatory engagement is embedded in sustainability principles ${ }^{82}$, and is broadly accepted at local levels. It should also apply at the global level. The fact that four of the planetary processes highlighted in Rockström et al. (2009) are beyond the boundaries shows that even when the information base enabling understanding of global change problems is comprehensive, society's choices about what to do about the problem are difficult, even intractable. Attention to decision-making processes must go hand in hand with technical advances.

\section{Equity and fairness in metrology - the development cooperation angle}

The Brundtland Report spells out just two key concepts for sustainability, the first of which resonates strongly with the equity debates currently taking place in the context of the Sustainable Development Goals, and the second of which relates closely to remaining within the 'safe operating space' for humanity:

- the concept of 'needs', in particular the essential needs of the world's poor, to which overriding priority should be given; and

- the idea of limitations imposed by the state of technology and social organisation on the environment's ability to meet present and future needs.

Since 'meeting people's needs' lies at the heart of sustainability, better links are needed between global scale insights and the needs of individual people wherever they are in the world. International cooperation should therefore be at the heart of global data gathering, analysis and application.

But there are several well-known problems with global change measurement, many of which have already been mentioned in this report. Bluntly, 'The rules of the game are loaded against developing countries'83. First of all, data on global change processes are not gathered evenly around the world. This matters more for some processes and variables than others, but regardless, it means that our collective process understanding is based on a partial view of the biophysical world.

Information about global change processes (stored in natural history collections, library materials, data centres and so on) is not distributed evenly around the world. Most data, by far, on the processes highlighted in this report are stored in the developed world. There are difficulties in transferring data to - and from - developing countries: most data are not digitized, or the capacity to handle digital information is lacking, or both.

Despite major improvements in recent rounds, the IPCC's global synthesis assessments retain an inbuilt bias in terms of geographical coverage, arising because its claims for legitimacy and accountability are related to its commitment to examine only peer-reviewed publications. Most scientific research is published in, and about, developed countries, providing both the evidence base and the pool of authors for these assessments.

Less economically developed countries have fewer people working on environmental change research and policy, both in absolute and relative terms. It is harder to maintain capacity in

\footnotetext{
${ }^{82}$ Agenda 21, sustainabledevelopment.un.org/content/documents/Agenda21.pdf; and the Rio Principles of the 1992 Rio Declaration, www.unesco.org/education/nfsunesco/pdf/RIO_E.PDF

${ }^{83}$ As articulated by Martin Khor of the South Centre, www.scidev.net/global/climate-change/news/indian-climate-experts-slamlatest-ipcc-report.html
} 
professional training and experience for this smaller pool of individuals. They face issues to do with technical connectivity to international information networks, resource availability for research and information exchange, and all the 'soft' issues relating to interpersonal networking between groups and individuals.

Securing reliable data and information underpins sustainable development. Investment in information and communication technologies can play a part, but they are not always the most costeffective choice where technical infrastructure is limited. More personalised and local-level options, such as mobile phone systems, are expanding rapidly, changing the kinds of information that are available for global change measurement, monitoring and management. There is immense scope for new approaches and applications using these kinds of development. ${ }^{84}$

The post-2015 sustainable development agenda is presenting new challenges for the global statistics and environmental change measurement community. A measuring framework will be required for the new goals. This will build on existing indicators, but new areas may also demand concerted attention. These include environmental-economic accounting, a widened set of social and environmental statistics, international trade registers and economic globalization statistics, 'big data' and citizen science systems.

There are signals of a shift in attention from relative, or efficiency-based, approaches to sustainable development, and absolute perspectives on environmental changes, such as the planetary boundaries framework. Absolute perspectives force attention to equity issues, making global distribution of knowledge, skills and data all critical elements for the implementation of a sustainability monitoring framework and highlighting quality infrastructure issues in the light of the SDG process and other international policy and development cooperation efforts.

\section{'Many kinds of knowledge': new debates about knowledge co- development}

In the context of the Convention on Biological Diversity (and elsewhere), global debates have focused prominently on the role of traditional, indigenous and local knowledge and its relationship to technoscientific knowledge in decision-making processes. For example, within IPBES, the member states have demanded that the platform 'should recognize and respect the contribution of indigenous and local knowledge to the conservation and sustainable use of biodiversity and ecosystems'. Input from local, traditional and indigenous communities is intended to contribute to assessments of biodiversity and ecosystem services, and generate the knowledge base for informed decisionmaking. These forms of knowledge should also be engaged in processes of identifying relevant policy tools for conservation and sustainable use, and for capacity building.

Efforts are needed to develop functioning mechanisms for legitimate, transparent, and constructive ways of creating synergies across these disparate knowledge systems. The Multiple Evidence Base (MEB) approach has been developed ${ }^{85}$, enabling diverse knowledge systems to contribute on their own terms to an enriched picture of the world that links qualitative and quantitative knowledge and understanding. The MEB approach (figure 16) seeks to secure legitimacy, credibility and salience by supporting an extended dialogue process. This dialogue engages policy people and researchers with expertise on various aspects of the environmental problem, and representatives of indigenous peoples and local communities affected by the issue to be debated. These diverse knowledge systems are viewed as generating different manifestations of valid and useful forms of knowledge. In the MEB approach, there is not necessarily a requirement for complete consensus as the outcome. The principles underlying the approach are of mutual respect, reciprocity and equity in the knowledge sharing and social learning processes.

\footnotetext{
84 Ad-hoc Strategic Coordinating Committee on Information and Data (2011) Interim Report, International Council for Science. www.icsu.org/publications/reports-and-reviews/strategic-coordinating-committee-on-information-and-data-report/ad-hocstrategic-coordinating-committee-on-information-and-data

85 Tengö, M. et al. (2013) Connecting diverse knowledge systems for enhanced ecosystem governance: the Multiple Evidence Base approach, Ambio DOI 10.1007/s13280-014-0501-3, http://link.springer.com/content/pdf/10.1007\%2Fs13280-014-0501-3.pdf
} 


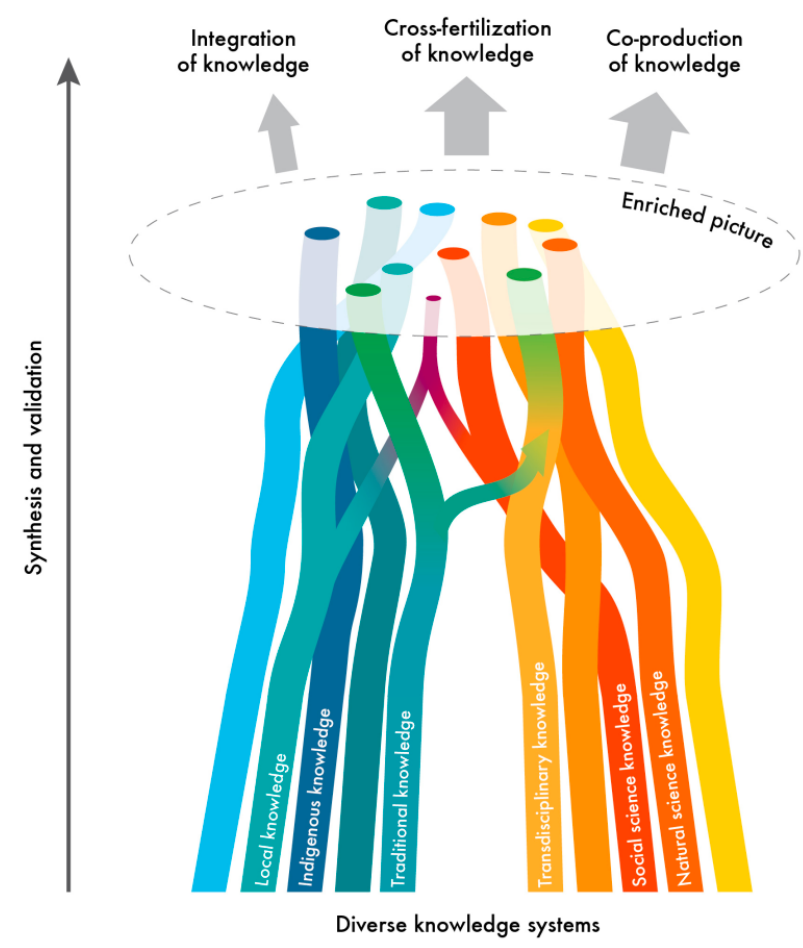

Figure 16 - The Multiple Evidence Base approach (figure by J. Lokrantz/Azote).

\begin{abstract}
Diverse knowledge systems - represented as different coloured strands in the figure - should be seen as complementary, contributing to an enriched picture of the real world. Innovations can be gained from cross-fertilization between systems. The MEB approach involves establishing partnerships between relevant communities, organisations and networks; investigating common interests and concerns, including power relations among the different actors; and acknowledging differences in experiences, methods, and goals, while bringing together all knowledge on an equal platform.
\end{abstract}

\title{
4. Closing thoughts
}

All human activities for progress and economic development are founded on Earth's natural resources and ecosystems. Although human activities are transforming these ecosystems, human adaptability has so far veiled many direct impacts of these changes. Humanity now faces the choice of raising future environmental risks or investing in our ecological infrastructure.

Recent planetary boundaries research provides stronger evidence of systemic thresholds and biophysical regime shifts. It characterizes the long-term context of current changes better ('the Anthropocene'), and brings human needs and decision-making into the heart of the issue. Above all, it argues in favour of strong and rapid reductions in the current levels of human perturbation of planetary processes.

Tracking change in these processes is a pressing global quality infrastructure issue. This report has given a flavour of the current state of that infrastructure for climate change, biodiversity, biogeochemical cycles and chemical pollution. Here we flag a few issues where the science and policy communities dealing with global change could benefit from further debate, and in some cases cultural change.

- The science-policy interface has received much attention, but the interface between science and wider society has received much less - especially the links between science and business, which is a powerful and influential actor in these global change processes. Lessons 
can and probably should be learned about collaboration, the degree of control of different elements of the quality infrastructure, and the comparability and integratability of data produced in and for these different sectors of society.

- Data issues are undervalued by most global change researchers, and are generally not given enough priority in the professional development of scientists. 'Mission challenge' can be a problem: universities are not equipped to be data archivists, and data centres are often focused more on archiving than on data use and usability. Global data needs can be seen as clashing with individual researcher interests. There is still ignorance and apathy about the actual resource needs for a global infrastructure, leading to a vicious circle - data management needs to be seen to be valuable in order to be supported. The concept of data publication is slowly being recognised as part of scholarly communication, as technologies enable supplementary information to be published alongside the journal articles that are the bedrock of academic careers.

- For some areas, notably global climate modelling and Earth observation, there is now largescale coherence in quality infrastructure requirements, but there is still very limited capacity when it comes to local and regional scale data. There are particular difficulties in the quality infrastructure for multidisciplinary sciences, especially at the global level.

- More work must be done to clarify the advantages provided by quality infrastructure elements such as standardization and certification, and to demonstrate the worth of the associated effort. This could involve an expanded remit of professional institutes and similar organisations - their members would benefit from increased confidence in the integrity and usability of data products.

- Standardization for global change process information needs to be seen as a process with stakeholder engagement. In commercial contexts, the relationship between quality management and customer requirements is accepted as lying at the core of infrastructure planning. In global change science and policy, data sets produced for one context often need to be repurposed for another. To ensure that this does not entail misapplication, misunderstanding and misuse, there is no substitute for meaningful engagement between data providers and users, with deepened dialogue and mutual learning. 


\section{For more information, go to www.stockholmresilience.su.se}

FUNDED BY

MISTRA 